Revista Brasileira de Meteorologia, v.23, n.2, 239-263, 2008

\title{
ENERGIA ESTÁTICA SOBRE O NORTE E NORDESTE DO BRASIL RELACIONADA COM A TEMPERATURA DA SUPERFÍCIE DO MAR
}

\author{
${ }^{1}$ ANA CLEIDE NASCIMENTO BEZERRA, ${ }^{2}$ ENILSON PALMEIRA CAVALCANTI
}

${ }^{1}$ Sistema de Proteção da Amazônia - Centro Técnico Operacional de Manaus (SIPAM - CTO/Mn). Avenida do Turismo 1350, Tarumã, Manaus - AM, Brasil

ana.bezerra@sipam.gov.br

${ }^{2}$ Universidade Federal de Campina Grande - Centro de Tecnologia e Recursos Naturais - Unidade

Acadêmica de Ciências Atmosféricas (UFCG - CTRN - UACA). Avenida Aprígio Veloso 882, Bodocongó, Campina Grande - PB, Brasil

enilson@dca.ufcg.edu.br

Recebido Maio 2006 - Aceito Setembro 2007

\begin{abstract}
RESUMO
A partir de fontes aparentes de calor e do sumidouro aparente de umidade, foram investigadas as características da circulação atmosférica de grande escala, nas regiões Norte e Nordeste do Brasil (NEB), relacionadas com a variabilidade da temperatura da superfície do mar (TSM) nos oceanos Atlântico e Pacífico Tropicais. Foram utilizados dados mensais das variáveis temperatura, umidade específica, componente zonal e meridional do vento e altura geopotencial (gpm) gerados pelo National Centers for Environment Prediction/National Center for Atmospheric Research (NCEP/NCAR). Os dados utilizados encontram-se espaçados numa grade de $2,5^{\circ} \times 2,5^{\circ}$ latitude e longitude, para os níveis padrão de 925 a $100 \mathrm{hPa}$. Além disso, também foram utilizados dados de TSM, numa grade de $2^{\circ} \times 2^{\circ}$ de latitude e longitude. Foram escolhidos quatro episódios de El Niño-Oscilação Sul (ENOS) e quatro de padrão de dipolo. O estudo refere-se ao trimestre de fevereiro-abril do período chuvoso. Durante os episódios quentes (frios), El Niño e dipolo positivo (La Niña e dipolo negativo), a atmosfera das áreas 1 e 2 (área 1 - centro Norte e área 2 - centro do Nordeste do Brasil) apresentaram-se menos (mais) úmidas. As variações observadas acima (abaixo) da média na energia estática seca, foram mais fortes durante os anos de El Niño (La Niña) do que durante os anos de dipolo positivo (dipolos negativos). Foram encontradas, menores (maiores) áreas de convergência de energia estática em baixos níveis e divergências em altos níveis durante os anos de El Niño (La Niña). Durante a fase positiva (negativa) dos dipolos, a faixa de convergência de energia estática sobre o Oceano Atlântico, foi observada mais ao norte (ao sul). A região Amazônica, apesar da atuação dos episódios de El Niños, La Niña, dipolos positivos e negativos, comportou-se como um sumidouro de vapor d'água. Já, região do NEB, como uma fonte aparente de vapor d'água durante os anos de El Niño e dipolo positivo e sumidouro para os anos de La Niña e Fase negativa do dipolo.
\end{abstract}

Palavras-chave: Energia estática, ENOS, Dipolo do Atlântico

ABSTRACT: STATIC ENERGY IN THE NORTH AND NORTHEAST OF BRAZIL RELATED WITH THE SEA SURFACE TEMPERATURE

Some aspects of the large scale atmospheric general circulation, in the North and Northeast Brazil, which are related to the Sea Surface Temperature (TSM) of the Tropical Atlantic and Pacific oceans were investigated from the apparent heat source and the humidity sink. Were utilized the monthly data variables temperature, specific humidity, zonal and meridional wind components and geopotential height from National Centers for Environment Prediction/National Center for Atmospheric Research (NCEP/NCAR). The used data are spaced in a grating of $2.5^{\circ} \times 2.5^{\circ}$ latitude and longitude, for the standard levels from 925 to $100 \mathrm{hPa}$. Besides, the used are TSM data from a $2^{\circ} \times 2^{\circ}$ latitude and longitude grid. Four episodes of ENSO and four of dipole pattern were selected. The study refers to 
the rainy quarter period of February to April. During the warm (cold) episodes of El Niño and positive dipole (La Niña and negative dipole) the atmosphere over the areas 1 and 2 (1-Noth and 2- Northeast of Brazil) were less (more) humid. The observed above (below) mean variations in the dry static energy were more stronger during the El Niño (La Niña) years when compared to the years of positive dipole (negative dipole). Smaller (larger) areas of convergence of dry static energy in the lower levels and divergence in the upper levels during the years of El Niño (La Niña) were encountered. During the positive (negative) dipole phases the convergence band of static energy over the Atlantic Ocean was observed more towards north (south). The Amazon region behaved as an apparent water vapor sink during the episodes of El Niño, La Niña and dipoles positive and negative. The Northeast Brazil region behaved as an apparent water vapor source during the episodes of El Niño and positive dipole years and as a sink during the episodes of La Niña and negative dipole year.

Key-words: Static energy, ENSO, Dipolo of Atlantic Ocean

\section{INTRODUÇÃO}

As regiões Norte e Nordeste do Brasil estão confinadas na região tropical, área caracterizada por apresentar uma atmosfera úmida com grande e intensa atividade convectiva, devido à disponibilidade de energia solar durante todo ano. Localizadas ao norte da América do Sul, onde se encontra a maior floresta úmida do mundo, a qual abrange nove países Sul Americanos. A parte brasileira da floresta Amazônica representa mais de $90 \%$, e inclui a região norte e parte da região nordeste.

A região da Amazônia é conhecida como sumidouro de umidade, sua precipitação é conseqüência de sua própria evapotranspiração (Marengo et al., 2001) e fluxos de vapor d'água trazidos do Oceano Atlântico [Salati et al., (1979) citado por Fisch e Nobre (1996)]. Diferentes técnicas têm sido utilizadas para determinação do balanço hídrico da região por diversos pesquisadores, tais como: Molion (1975), Villa Nova et al. (1976), Marques (1978), Salati et al. (1979), Marques et al. (1980), Rocha (1991) e Matsuyama (1992) citados por Fisch e Nobre (1996). Schaak et al. (1990) citado por Silva Dias (1999), usando análises meteorológicas em pontos de grade, localizaram no globo as principais fontes de calor associadas à liberação de calor latente de origem convectivo, e umas delas foi a região Amazônica.

No entanto, Rocha (1991), citado por Rocha (2001), sugere que durante o período de estiagem (julho a setembro), a atmosfera da região Amazônica comportase como fonte de vapor d'água, transportando para o Hemisfério Norte pelo setor noroeste e para a região sudeste da América do sul pelo setor sudoeste e sul dessa região.

Em função das diferentes características físicas apresentadas pelo clima da região Nordeste do Brasil (NEB), está é afetada por períodos de secas severas e enchentes, e dependendo do setor de atividade, pode trazer grandes prejuízos a região (Rebouças, 1997).

Há décadas vêm sendo estudados os aspectos energéticos na circulação geral da atmosfera, com o intuito de se entenderem os processos dinânimos causadores das secas e enchentes sobre as regiões Norte e NEB. Silva Marques et al. (1983) usando dados de ar superior sobre a área do NEB, encontraram importação no fluxo de vapor d'água no período chuvoso e exportação no período seco. Durante o mês seco e normal, a atmosfera do NEB comporta-se como fonte de vapor d'água, e no mês chuvoso, como sumidouro (Cavalcanti, 1986).

Recentemente no trimestre março-abril-maio, modelos como "Regional Atmospheric Modeling System" - RAMS tem sido utilizados para estudar o teor e o transporte de vapor d'água atmosférico integrado na vertical sobre o NEB. Vale salientar, que durante o trimestre analisado observa-se a presença dos ventos alísios transportando umidade do Oceano Atlântico Tropical para dentro da região (Cavalcanti et al., 2002).

A variabilidade das chuvas na região Nordeste na época chuvosa é diretamente influenciada pelas temperaturas das superfícies de ambos os oceanos tropicais, Atlântico e Pacífico, que modulam o posicionamento da Zona de Convergência Intertropical (ZCIT), que é o principal sistema causador de precipitação do Norte e Nordeste. Na Amazônia, a ZCIT e suas interações com outros sistemas contribuem com aproximadamente $70 \%$ da precipitação (Rocha, 2001).

A ZCIT é caracterizada por uma região de interações atmosféricas e oceânicas, como Zona de Confluência dos Alíseos (ZCA), zona do cavado equatorial, zona de máxima temperatura da superfície do mar, zona de máxima convergência de massa e máxima cobertura de nuvens convectivas (Ferreira, 1996). Sobre o Atlântico, é caracterizada pelo deslocamento norte-sul ao longo do ano, migrando de sua posição mais ao norte, cerca de $8^{\circ} \mathrm{N}$ durante o verão do Hemisfério Norte (HN), para a posição mais ao sul, cerca de $1^{\circ} \mathrm{S}$, durante o mês de abril (Hastenrath e Heller, 1977).

Outros estudos científicos realizados por inúmeros pesquisadores, como Hastenrath e Heller (1977), Moura e Shukla (1981), Nobre e Shukla (1996), Brabo et al. (1993), e Uvo (1998), mostram resultados de que os Oceanos Pacífico e Atlântico têm influência no regime chuvoso 
do outono no leste da Amazônia e Nordeste Brasileiro.

As condições atmosféricas e oceânicas sobre o Oceano Pacifico, que se observam quando não é detectada a presença de fenômenos extremos (El Niño ou La Nina), indicam águas superficiais relativamente mais aquecidas no Pacífico Equatorial oeste, próximo à costa australiana e região da Indonésia, e relativamente mais frias junto à costa oeste da América do Sul. Nestas circunstâncias, o ar sobe devido às águas quentes (áreas de baixa pressão), ocorrendo fortes chuvas sobre essa região, e desce sobre o oceano (área de altas pressões), nas proximidades da costa sul-americana, onde as chuvas são escassas. Esse movimento do ar das áreas de alta pressão para as de baixa pressão atmosférica sobre o Pacífico Equatorial é denominado "Célula de Walker".

Os ventos alísios sopram de NE e SE conhecidos como célula de Hadley. Um fluxo é formado de leste para oeste na área do Pacífico equatorial, varrendo as águas superficiais, dando lugar às águas profundas para aflorarem a superfície. Este mecanismo é chamado de ressurgência, próximo à costa oeste da América do sul. Na presença do El Niño, a intensidade dos ventos alísios diminui chegando em certo momento, a mudar de sentido, ou seja, de oeste para leste. Sem a força dos alísios, o acumulo de água aquecida no lado oeste do Pacífico espalha-se pelo Oceano Pacífico Equatorial central, chegando até o litoral Peruano tornando a termoclina (variação brusca de temperatura em uma determinada profundidade do mar ou em ambientes de água doce) da região mais profunda.

$\mathrm{Na}$ Austrália, as áreas onde havia bastante chuva passam a ser observadas secas, enquanto que as chuvas que deveriam estar precipitando são verificadas sobre o oceano, nas proximidades da Polinésia. Ao mesmo tempo, as chuvas que eram observadas próximo ao litoral sul-americano adentram o continente e passam a cair no interior do Peru. $\mathrm{O}$ ar que sobe provocando as precipitações no Peru vai descer seco exatamente na região litorânea do Nordeste Brasileiro, diminuindo as chuvas nessa região.

As condições EI Niño e La Niña abrangem uma grande variabilidade. Quinn et al. (1978) introduziram quatro categorias de EI Nino (forte, moderado, fraco, e muito fraco), no entanto, há diferenças consideráveis dentro de cada categoria e, o episódio começa a se desenvolver em meados de um ano, atinge sua máxima intensidade no final do mesmo ano e dissipa-se em meados do ano seguinte.

No Atlântico tropical, Marengo et al. (1993) observaram, que durante anos de grande aquecimento das águas do Pacifico equatorial central (fenômeno do El Niño), a ZCIT encontra-se anomalamente mais ao norte de sua posição normal, assim os ventos alíseos de NE são mais fracos, reduzindo a umidade que penetra para o interior da região Amazônica.

Na escala interanual, o Padrão de Dipolo na TSM é o modo de variabilidade mais importante da variação climática sobre o Atlântico Tropical durante o outono (Nobre, 1993, citado por Souza, 1997). Entretanto, os fenômenos atmosféricos e oceânicos que ocorrem na bacia do Atlântico Tropical têm mais efeitos significativos no clima do Nordeste do Brasil do que os observados no Pacífico (Hastenrath et al., 1987). No entanto, embora a variabilidade interanual das TSM e ventos sobre o Atlântico Tropical sejam significativamente menores do que aquela observada no Pacífico Equatorial, essas variáveis têm profunda influência na variabilidade climática da América do Sul, principalmente sobre a Região Nordeste do Brasil (Hastenrath, 1984; Nobre e Shukla, 1996).

Zebiak (1993) mostra que parte da variabilidade interanual do Atlântico é atribuída ao modo equatorial e sugere que este pode iniciar-se de forma rápida, em escalas de poucas semanas a meses, por causa da excitação e propagação de ondas de Kelvin e Rossby equatorial forçadas pelo vento.

As regiões mais afetadas pelas circulações atmosféricas e oceânicas do Oceano Atlântico Tropical são: O leste da Amazônia (Nobre e Shukla, 1996); o NEB (Hastenrath e Heller, 1977; Moura e Shukla, 1981; Nobre, 1993 citado por Souza, 1997; Rao et al., 1993; Nobre e Shukla, 1996) e o sul do Brasil e Uruguai (Diaz e Studzinski, 1994, citado por Nobre, 1996.

Moura e Shukla, 1981 também encontraram a ocorrência simultânea de anomalias de TSM quente ao norte e anomalias de TSM fria ao sul do Atlântico equatorial relacionadas à secas sobre o NEB. A correlação positiva encontrada sobre o sul do Atlântico é explicada de maneira que a presença de anomalias de TSM com sinais contrários, positiva ao norte e negativa ao sul, geram a estrutura simultânea de uma fonte de calor sobre o Atlântico norte e um sumidouro de calor anômalo sobre o Atlântico Sul. Assim, a banda de nebulosidade convectiva associada à ZCIT na área equatorial intensifica-se ao norte causando um movimento descendente sobre a região do NEB e junto ao sul do Oceano Atlântico anomalias de TSM abaixo da média, reduz evaporação e o fluxo convergente de umidade, assim diminuindo a precipitação sobre na região.

Estudos sobre a relação entre o ENOS e os modos de variabilidade de TSM no Atlântico tropical descrevem que o modo gradiente de anomalias de TSM pode ser forçado remotamente pelo ENOS (Saravanan e Chang, 2000, Sutton et al, 2000, citados por Silva, 2006). Enfield e Mayer (1997) analisaram as estruturas espacial e temporal da variabilidade de TSM no Atlântico tropical relacionando-as com a variabilidade de TSM no Pacífico equatorial, concluindo que a variabilidade de TSM no Pacífico equatorial está mais fortemente correlacionada com a variabilidade da TSM do Atlântico tropical na escala interanual, ao longo da região de $10^{\circ} \mathrm{N}-20^{\circ} \mathrm{N}$. O aquecimento nesta região ocorre em torno de 4-5 meses após a fase madura do evento quente no Pacífico, em resposta à redução da velocidade 
dos ventos alísios de nordeste em superfície. Isto leva a reduzir o fluxo de calor latente e sensível sobre a região em questão (Enfield e Mayer, 1997, citado por Silva, 2006).

A influência do ENOS no Atlântico tropical é observada durante a primavera boreal (março-maio) (Enfield e Mayer, 1997, Saravanan e Chang, 2000, ciatdos por Silva, 2006) e está associada com anomalias na circulação de Walker. O ENOS contribui de forma significativa para a correlação entre a estrutura de dipolo do Atlântico e a precipitação do norte do NEB (Saravanan e Chang, 2000).

Inúmeras pesquisas vêm sendo realizadas com objetivo de conhecer melhor a dinâmica dos fenômenos que afetam o clima. Quanto mais características são identificadas dessa dinâmica, mais confiáveis tornam-se as previsões. A dinâmica dos oceanos vem se tornando cada vez mais rica em informações sobre os componentes anômalos que afetam o clima das regiões adjacentes. Um dos principais objetivos desse trabalho é enriquecer a nossa literatura, sobre as conseqüências desses fenômenos, os quais possuem grande influência sobre as regiões do Norte e Nordeste do Brasil.

\section{DADOS E METEOROLOGIA}

\subsection{Dados}

Neste estudo são utilizados dados mensais, do período de 1958 a 1998, obtidos no National Centers for Environment Prediction/National Center for Atmospheric Research (NCEP/ NCAR), espaçados em uma grade de $2,5^{\circ} \times 2,5^{\circ}$ latitude e longitude, que consiste em um sistema de assimilação dos dados do Projeto reanalysis (incluem módulos de controle de qualidade, análise objetiva e interpolação), descritos com mais detalhes em Kalnay et al. (1996) e Kistler et al. (2001). As variáveis utilizadas são: temperatura $(\mathrm{K})$; umidade específica $(\mathrm{kg} / \mathrm{kg})$; componente zonal (u) e meridional $(\mathrm{v})(\mathrm{m} / \mathrm{s})$ do vento e altura geopotencial (gpm), para os níveis padrão de $925 \mathrm{hPa}$ a $100 \mathrm{hPa}$.

Além das variáveis atmosféricas descritas acima, foram utilizados dados de TSM para o período de 1950 a 1999, gerados por Reynolds e Marsizo (1992), com a finalidade de escolher os anos estudados. O critério de seleção adotado foi que os padrões observados na TSM do Pacífico e do Atlântico Tropical, tenham anomalias significativas (no Atlântico, persistência de anomalias de $1^{\circ} \mathrm{C}$ por mais de um mês). Estes dados foram obtidos do National Meteorological Center (NMC), atual NCEP, e encontram-se espaçados numa grade de $2^{\circ} \times 2^{\circ}$ de latitude e longitude (Detalhes em Reynolds, 1988; Reynolds e Marsico, 1992). A série de dados foi completada por dados obtidos pelo Climate Prediction Center, até Julho de 2003.

\subsection{Metodologia}

Para seleção dos eventos, foram calculadas médias mensais de TSM sobre áreas de ocorrências dos El Niño 3 e 3.4 (Figura 1), áreas que fornecem com mais certeza a intensidade dos episódios ENOS sobre o Oceano Pacífico Tropical, e sua fase de maturação ocorre durante os meses de novembro a janeiro (Trenberth, 1997) e Dipolo do Atlântico e, em seguida, foram calculadas suas anomalias, visualizadas na Figura 2, que serviram de base para facilitar a seleção dos eventos.

UVO (1998) encontrou diversas áreas da região Amazônica e NEB que se correlacionam em escala mensal e sazonal com ambas as áreas citadas acima.

A seleção dos episódios adotou os seguintes critérios: (a) Anomalias de TSM $\geq 1,0^{\circ} \mathrm{C}\left(\leq-1,0^{\circ} \mathrm{C}\right)$ para caracterização de um evento de El Niño (La Niña) durante a fase de maturação (novembro a janeiro segundo Trenberth, 1997) sobre as áreas do Niño 3 e 3.4; (b) Anomalias de TSM, que simultaneamente, apresentaram anomalias opostas sobre a Bacia norte e Bacia sul de $\pm 0,5^{\circ} \mathrm{C}$, principalmente, durante a estação de fevereiro a abril.

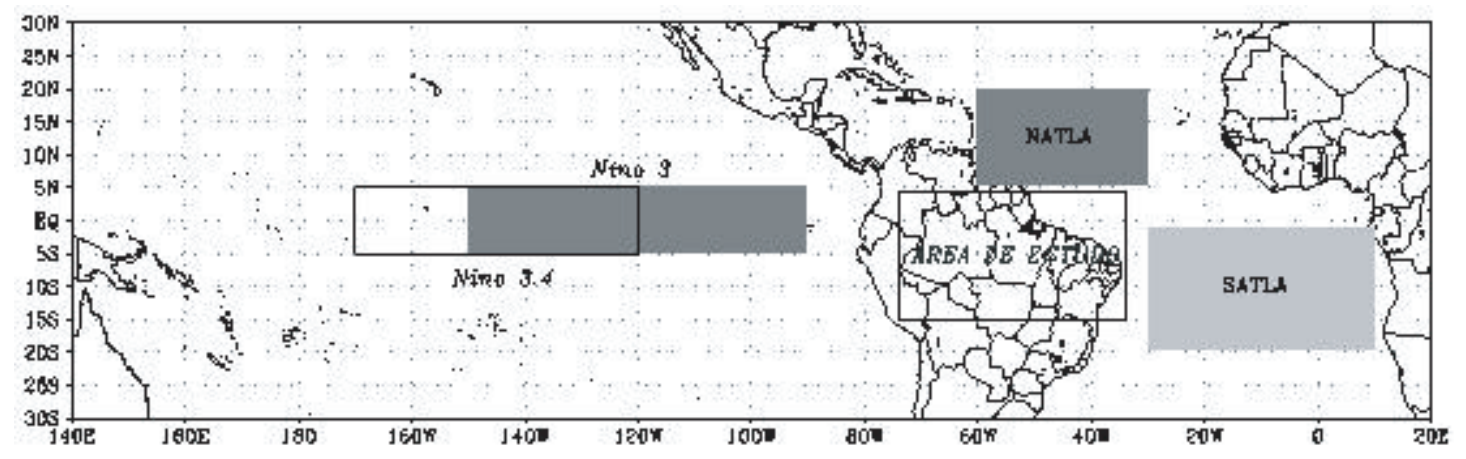

Figura 1 - Área de localização do El Niño $3\left(5^{\circ} \mathrm{N}-5^{\circ} \mathrm{S}, 150^{\circ} \mathrm{W}-90^{\circ} \mathrm{W}\right)$ e $3.4\left(5^{\circ} \mathrm{N}-5^{\circ} \mathrm{S}, 120^{\circ} \mathrm{W}-170^{\circ} \mathrm{W}\right)$, Dipolo do Atlântico (Norte: $5^{\circ} \mathrm{N}-20^{\circ} \mathrm{N}, 30^{\circ} \mathrm{E}-$ $60^{\circ} \mathrm{W}$; Sul: $\left.0^{\circ}-20^{\circ} \mathrm{S}, 30^{\circ} \mathrm{W}-60^{\circ} \mathrm{W}\right)$ e área de estudo 
Seguindo os critérios de seleção, foi possível escolher quatro episódios de ENOS e quatro de Padrão de Dipolo. Na Figura 2, são visualizados os anos escolhidos para este estudo. As áreas preenchidas com cinza escuro (cinza claro) representam os anos de El Niño (La Niña) e dipolos positivos (dipolos negativos).

Os episódios El Niño e La Niña selecionados (Tabela 1) estão de acordo com eventos discutidos por Delecluse et al.
(1994); Trenberth (1997) e Souza (2003). Semelhantemente, as Fases do dipolo positivo e negativo, sobre a bacia do Atlântico Tropical, identificadas acima, são também examinadas por Nobre e Shukla, 1996; Moura e Sukla, 1981 e Souza e Nobre, 1998.

O episódio de 1973/76 foi um evento longo, mas somente o ano de 1974 foi apresentado nos resultados. Se for necessário, serão citadas características presentes nos outros anos.

a)

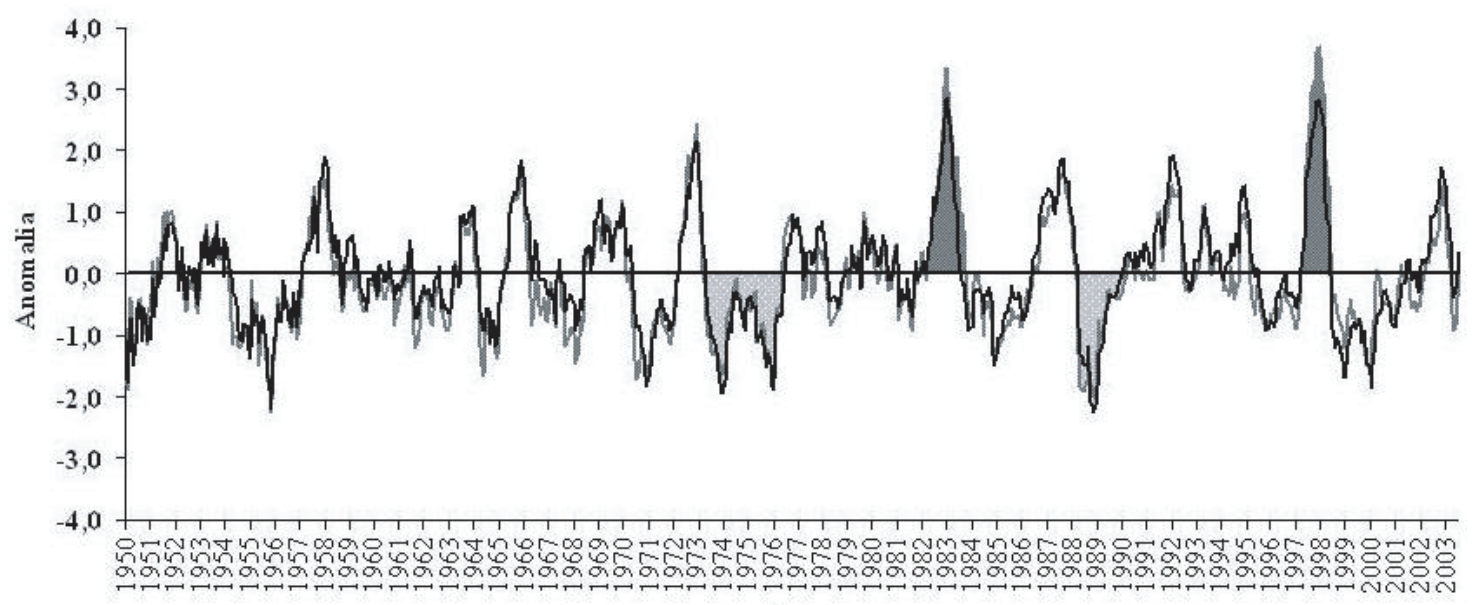

- Anomalia NINO3 $\quad$ Ano Anomalia NINO 3.4

b)

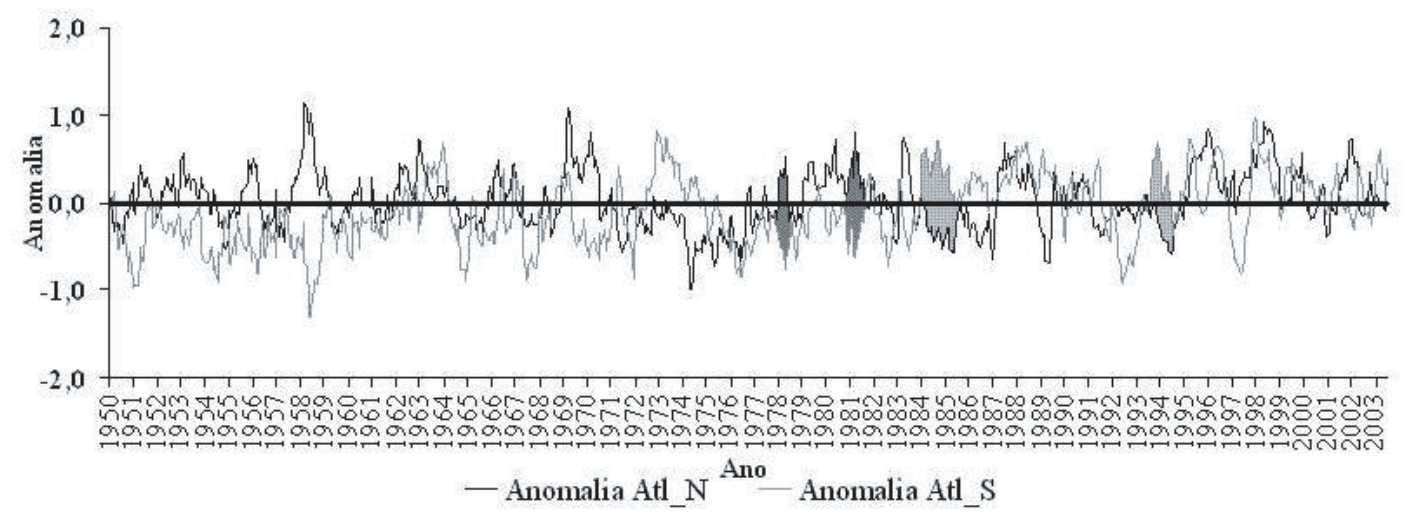

Figura 2 - Anomalias mensais de TSM dos Oceanos (a) Pacífico tropical na área do El Niño 3 e 3.4 e (b) Atlântico Norte (linha preta) e Sul (linha cinza)

Tabela 1 - Episódios selecionados para este estudo

\begin{tabular}{cccc}
\hline \multicolumn{2}{c}{ Oceano Pacífico } & \multicolumn{2}{c}{ Oceano Atlântico } \\
\hline El Niño & La Niña & Dipolo positivo & Dipolo negativo \\
\hline $1982 / 83$ & $1973 / 76$ & 1978 & 1985 \\
$1997 / 98$ & $1988 / 89$ & 1981 & 1994 \\
\hline
\end{tabular}


Foi utilizado um sistema de Visualização e Análise de Dados em Pontos de Grade (GrADS) - (Doty, 1995). É um software interativo utilizado nas tarefas de acesso, manipulação e visualização de dados geofísicos em geral. O GrADS trabalha com matrizes de dados nos formatos BINÁRIO, GR1B, NetCDF ou HDF-SDS, nas quais as variáveis podem possuir até 4 dimensões (longitude, latitude, níveis verticais e tempo) especificadas por um arquivo descritor.ctl. Atualmente, o GrADS é o software mais utilizado nos centros operacionais e de pesquisa meteorológica. O GrADS possui uma interface programável (scripting language) com a qual é possível se desenvolver sofisticadas análises, cálculos de variáveis derivadas e aplicações de visualização automática. Dentro dos scripts é possível se desenvolver a interatividade com funções, expressões ou rotinas externas escritas com outras linguagens de programação (FORTRAN, C, C++, UNIX Shell, etc) e também com linhas de comando do sistema operacional (MS-DOS, Windows, LINUX, UNIX) (Souza, 2004).

\subsection{Formulação Teórica}

As equações da energia estática seca, latente e úmida, expressa em $\mathrm{kJ} \mathrm{kg}^{-1}$, são dadas, respectivamente, por:

$$
\begin{aligned}
& S \equiv c_{P} T+\phi \\
& U \equiv L_{V} q \\
& h \equiv c_{P} T+\phi+L_{V} q
\end{aligned}
$$

Em que: $\mathrm{C}_{\mathrm{p}}$ é o calor específico à pressão constante $\left(c_{\mathrm{p}}=1004 \mathrm{~J} \cdot \mathrm{kg}^{-1} \mathrm{~K}^{-1}\right), \mathrm{T}$ a temperatura, $\oint$, o geopotencial, Lv o calor latente de vaporização ( $\left.\mathrm{Lv}=2,462 \times 10^{6} \mathrm{~J}_{\mathrm{kg}} \mathrm{kg}^{-1}\right)$ e q a umidade específica.

A equação para a energia estática seca e latente é expressa por Yanai et al. (1973) como:

$$
\begin{aligned}
& \frac{\partial S}{\partial t}+\nabla \cdot S \vec{V}+\frac{\partial S \omega}{\partial P}=Q_{H}+L_{V}(c-e) \\
& \frac{\partial L_{V} q}{\partial t}+\nabla \cdot L_{V} q \vec{V}+\frac{\partial L_{V} q \omega}{\partial P}=L_{V}(e-c)
\end{aligned}
$$

Em que:

$$
\frac{\partial S}{\partial t} \text { é a taxa de variação local de } S
$$

$\nabla . S \vec{V}$ é a divergência do transporte horizontal de S;

de S; $\frac{\partial S \omega}{\partial P}$ é taxa de variação vertical do transporte vertical $\mathrm{Q}_{\mathrm{H}}$ é a taxa de aquecimento ou resfriamento radiativo;

$\frac{\partial L_{V} q}{\partial t}$ é a taxa de variação local de $L_{V} q$; $\mathrm{L}_{\mathrm{V}} \mathrm{q}$;

$\nabla . L_{V} q \vec{V}$ é a divergência do transporte horizontal de de $\mathrm{L}_{\mathrm{V}} \mathrm{q}$;

$\frac{\partial L_{V} q \omega}{\partial P}$ é a taxa de variação vertical do transporte vertical

c é a taxa de condensação;

e a taxa de evaporação.

Uma vez que o estudo refere-se ao trimestre de fevereiroabril do período chuvoso, será abandonada a taxa de variação local e a taxa convectiva, desprezíveis quando comparados aos outros termos. Assim, a divergência dos fluxos, em unidade $\mathrm{kJ}_{\mathrm{M}}{ }^{-2} \mathrm{~s}^{-1}$, será avaliada pelas seguintes equações:

$$
\begin{gathered}
\nabla \cdot \vec{S}=\frac{\partial S_{\lambda}}{\partial x}+\frac{\partial S_{\phi}}{\partial y} \\
\nabla \cdot \vec{Q}=\frac{\partial Q_{\lambda}}{\partial x}+\frac{\partial Q_{\phi}}{\partial y}
\end{gathered}
$$

O fluxo de energia estática seca e latente para as áreas $1\left(2^{\circ} \mathrm{S}-7^{\circ} \mathrm{S} / 60^{\circ} \mathrm{W}-65^{\circ} \mathrm{W}\right)$ e $2\left(5^{\circ} \mathrm{S}-10^{\circ} \mathrm{S} / 37,5^{\circ} \mathrm{W}-42,5^{\circ} \mathrm{W}\right)$, foi obtido, multiplicando-se o valor médio da divergência pelas respectivas áreas (Figura 3) e são expressos em $\mathrm{KJs}^{-1}$. O motivo das escolhas das áreas 1 e 2 foi comparar o balanço de energia sobre uma área de característica tropical úmida e uma área semi-árida.

$$
\begin{aligned}
& \oint \vec{S} \cdot \vec{n} d L=\iint \nabla \cdot \vec{S} d A=\langle\nabla \cdot \vec{S}\rangle A \\
& \oint \vec{Q} \cdot \vec{n} d L=\iint \nabla \cdot \vec{Q} d A=\langle\nabla \cdot \vec{Q}\rangle A
\end{aligned}
$$

Em que: $\vec{n}$ é o vento normal às faces verticais da área; dL é o comprimento do contorno, descrito pela projeção das faces vertical da área, no plano horizontal; A é a área de $5^{\circ} \times 5^{\circ}$ de latitude e longitude; \langle\rangle$\equiv$ é a média na área A. 


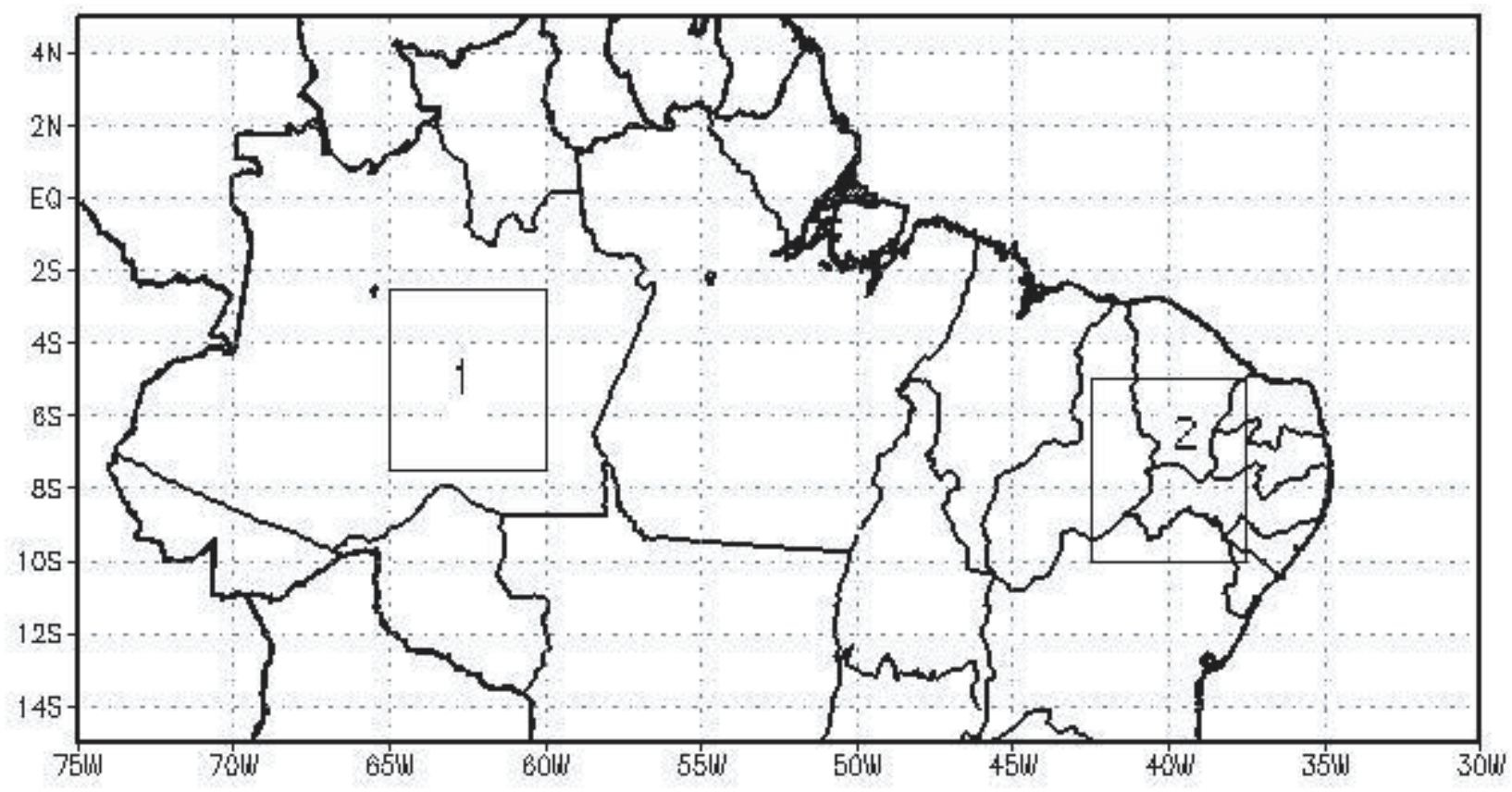

Figura 3 - Áreas 1: Norte e Área 2: Nordeste do Brasil.

\section{RESULTADOS}

\subsection{Perfis Verticais da Energia Estática seca, da úmida e da saturada}

A diferença entre o perfil vertical da energia úmida e da saturada nos oferece o comportamento da atmosfera quanto à saturação. Quanto mais próximas às linhas que representam os perfis verticais de energia estática úmida e da saturada, menor será a área, e, conseqüentemente, mais úmida e mais próxima da saturação encontra-se a atmosfera. Logo, seguindo este critério, obtiveram-se algumas características da atmosfera das duas regiões estudadas.

A energia estática seca, a úmida e a saturada está expressa em kJ.kg-1 e distribuída nos níveis de pressão de 925, 850, 700, 500, 300, 250, 200 e $100 \mathrm{hPa}$.

Observa-se nos perfis verticais climatológicos da média dessas energias (Figura 4), que sobre a área 1, a atmosfera apresenta-se ligeiramente mais úmida do que sobre a área 2. Essa característica já era esperada, pois a área 1 localiza-se sobre a região da maior floresta tropical úmida e a área 2 sobre a região semi-árida. Sabe-se que a atmosfera sobre floresta é bastante úmida, devido a sua alta evapotranspiração chegando a ser responsável por cerca de $50 \%$ das chuvas que a floresta recebe. O restante é originário de águas transportadas pelo vento do Oceano Atlântico, como parte do ciclo hidrológico da região [Salati et al. (1979) citados por Fisch et al. (1996)].
Essa observação pode ser comprovada com facilidade visualizando a área entre os perfis verticais da energia estática úmida e da saturada. Percebe-se que a área entre os perfis da energia estática úmida e da saturada é menor sobre a área 1 do que a observada sobre a área 2. Embora a área 2 seja de característica semi-árida, observa-se que a energia estática úmida aproxima-se do observado para a área 1, provavelmente devido ao suprimento de energia latente para o NEB pelo Oceano Atlântico.

Durante os anos de El Niño (La Niña) (Figura 5) e fase positiva do dipolo (fase negativa do dipolo) (Figura 6), foi visualizada nas áreas 1 (Figura 5a e 6a) e 2 (Figura 5b e 6b), uma atmosfera menos úmida (mais úmida).

A energia estática seca não apresentou variações de destaque durante os anos estudados, porém as pequenas variações visualizadas acima (abaixo) da média foram mais fortes durante os anos com episódios de El Niño (La Niña) do que durante os anos de dipolo positivo (dipolos negativos).

Quanto ao perfil vertical da energia estática úmida, foram encontrados resultados similares aos de Silva Marques (1983) e Cavalcanti (1986), tanto em ordem de grandeza quanto ao comportamento ao longo da atmosfera, ou seja, valores máximos nos níveis baixos e altos e, valores mínimos nos níveis médios, embora esses estudos tenham sido realizados com valores mensais.

Foram visualizados nos perfis de energia estática úmida durante os anos de El Niño e dipolo positivo ( $\mathrm{La}$ Niña e dipolo negativo) valores acima (abaixo) da média, 
sendo que, na área 2, os valores mínimos observados em níveis médios da atmosfera não variaram tanto quanto os encontrados na área 1, exceção apenas para o ano de 1985 (ano de dipolo negativo) em que, para níveis acima $850 \mathrm{hPa}$, apresentou o perfil da energia úmida acima da média.

$\mathrm{Na}$ análise comparativa entre os dois anos de mesma categoria, El Niños (1983 e 1998), La Niñas (1974 e 1989), dipolos positivos (1978 e 1981) e dipolos negativos (1985 e 1994), também foram visualizadas pequenas variações no perfil vertical da energia media trimestral de um episódio para o outro, na atmosfera das áreas 1 e 2.

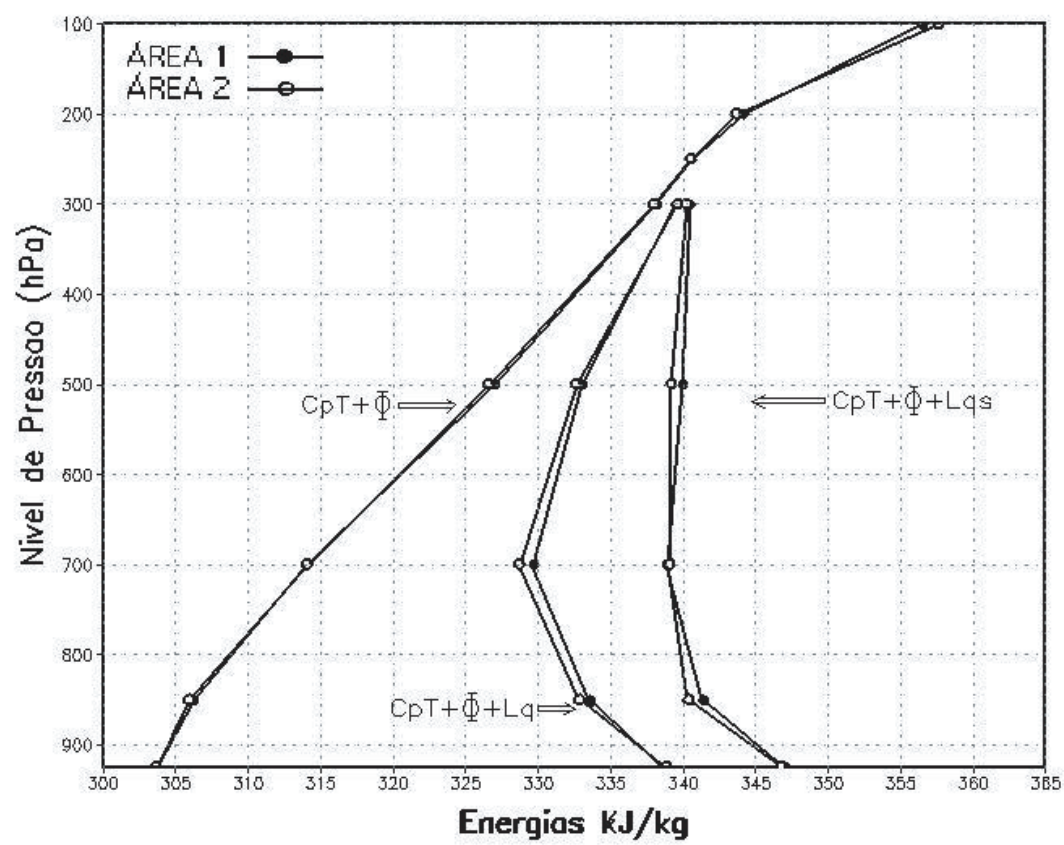

Figura 4 - Perfis verticais climatológicos das energias estáticas seca, úmida e saturada média do trimestre fevereiro-abril para as áreas 1 (círculos fechados) e 2 (círculos abertos)

\subsection{Divergência dos Fluxos de Energia Estática seca e latente}

De modo geral, as áreas onde se observaram convergências de fluxos dessas energias em baixos níveis estavam associadas a divergências em altos níveis, ou vice-versa. Para os meses estudados (período chuvoso), preferencialmente, ocorreram convergências em baixos níveis, que devido à continuidade de massa geraram movimentos verticais ascendentes, favorecendo o desenvolvimento de nuvens e, conseqüentemente, precipitação dada à disponibilidade de umidade. Entretanto, os episódios de El Niño, La Nina, e de dipolos positivo e negativo modularam esses efeitos dinâmicos sobre a região, tornando os períodos chuvosos mais ou menos intensos.

Observa-se nas Figuras 7 e 8, referentes aos episódios El Niño e La Niña, respectivamente, regiões em baixos níveis, com máxima convergência de energia estática seca e latente sobre o leste da Amazônia e o NEB.

Durante os anos de El Niño (Figura 7), em baixos níveis (altos níveis), foram visualizadas áreas de convergências (divergências) de fluxos de energia estática seca e latente sobre quase toda região Norte do Brasil e oeste e norte do NEB. Observaram-se valores máximos sobre o oeste central da região do NEB e divergência sobre o litoral leste do NEB estendendose para o Oceano Atlântico. Em 1998 (Figura 7b), a área de divergência em baixos níveis encontrada sobre Amazônia atingiu o sudoeste, o oeste, o nordeste e o centro do Estado. Nas camadas de $850-700 \mathrm{hPa}$ a $500-300 \mathrm{hPa}$, a divergênciade energia estática estendeu-se por grande parte do NEB.

Em geral, foram observadas divergência de energia estática latente sobre o leste do NEB na camada $850-700 \mathrm{hPa}$, todo o NEB na camada 700-500hPa durante os anos de El Niño e La Nina. Na camada de 500-300hPa em anos de El Niño, a divergência foi visualizada sobre todo o NEB (exceto o litoral norte) e em La Niña sobre o sul e leste da região.

Nos dois episódios de La Niña (Figura 8), a área de máxima convergência visualizada em baixos níveis sobre as regiões Norte e NEB, estende-se para leste atingindo uma área 


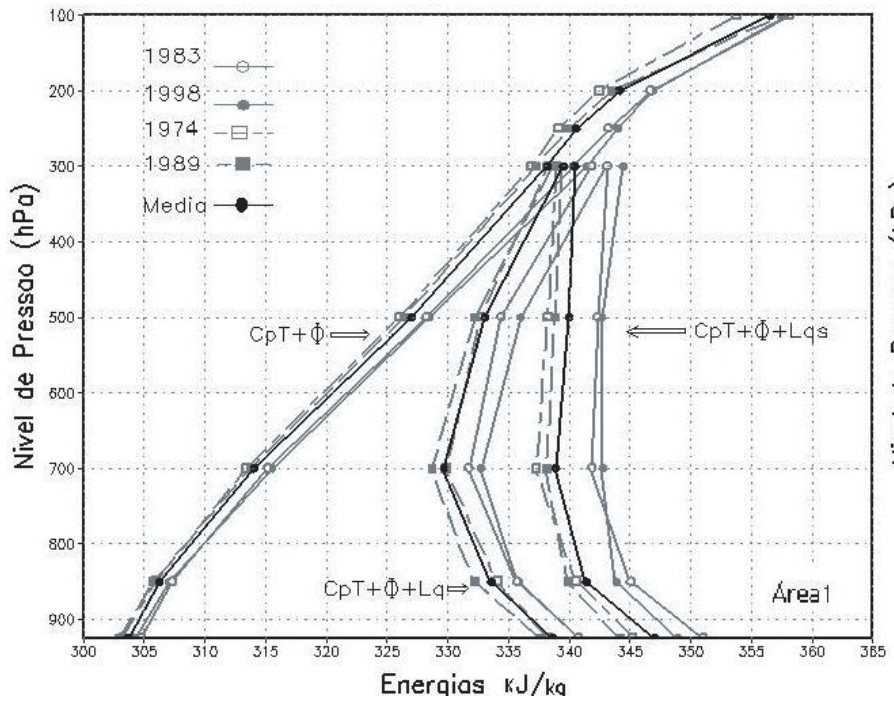

a)

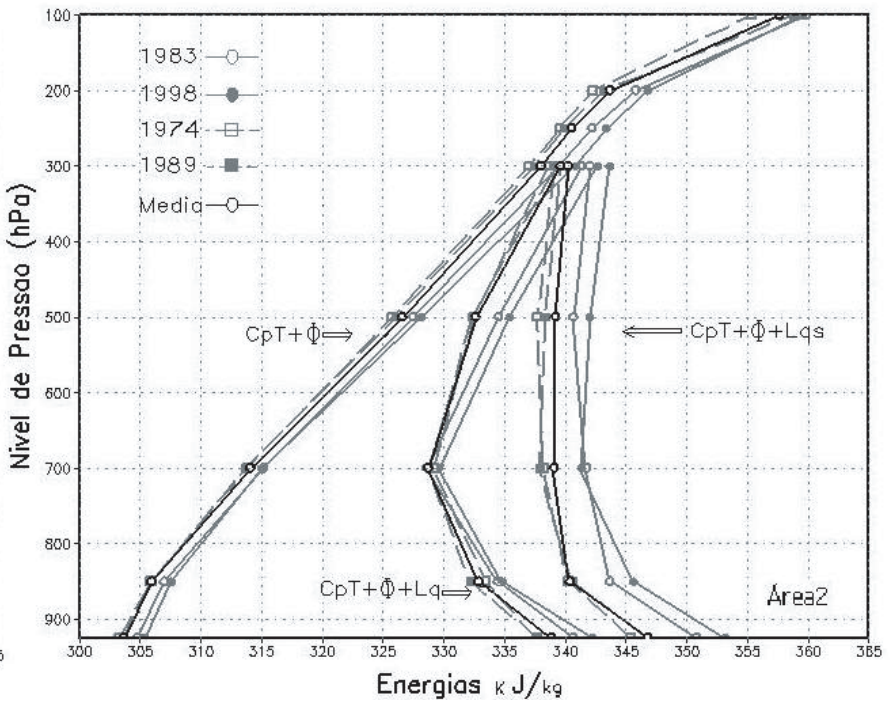

(b)

Figura 5 - Perfis verticais das energias estáticas seca, úmida e saturada média do trimestre fevereiro-abril para as áreas 1(a) e 2(b) durante episódios de El Niño (linhas continuas) e La Niña (linhas tracejadas)

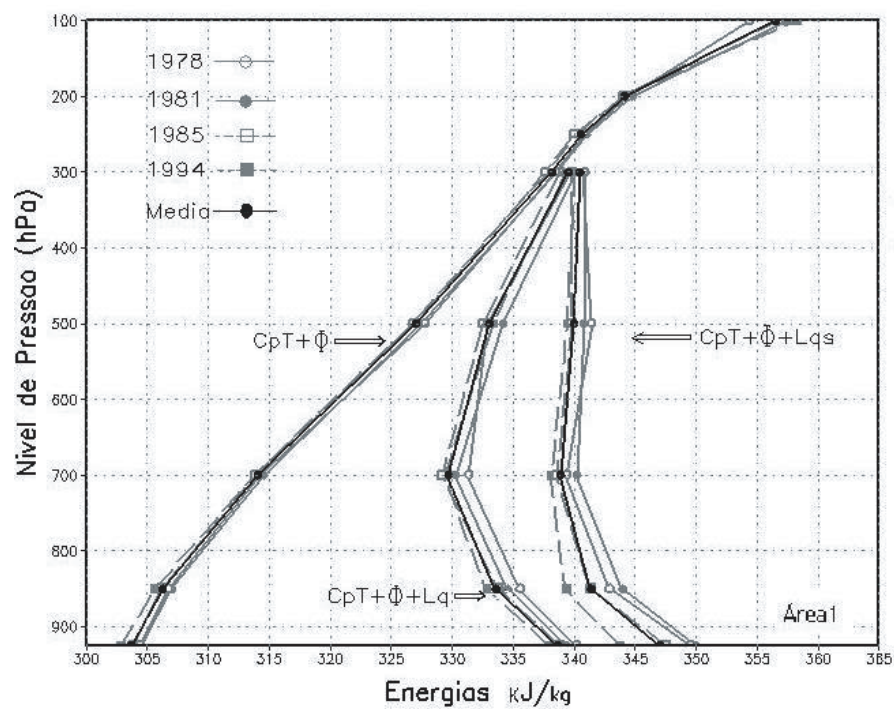

a)

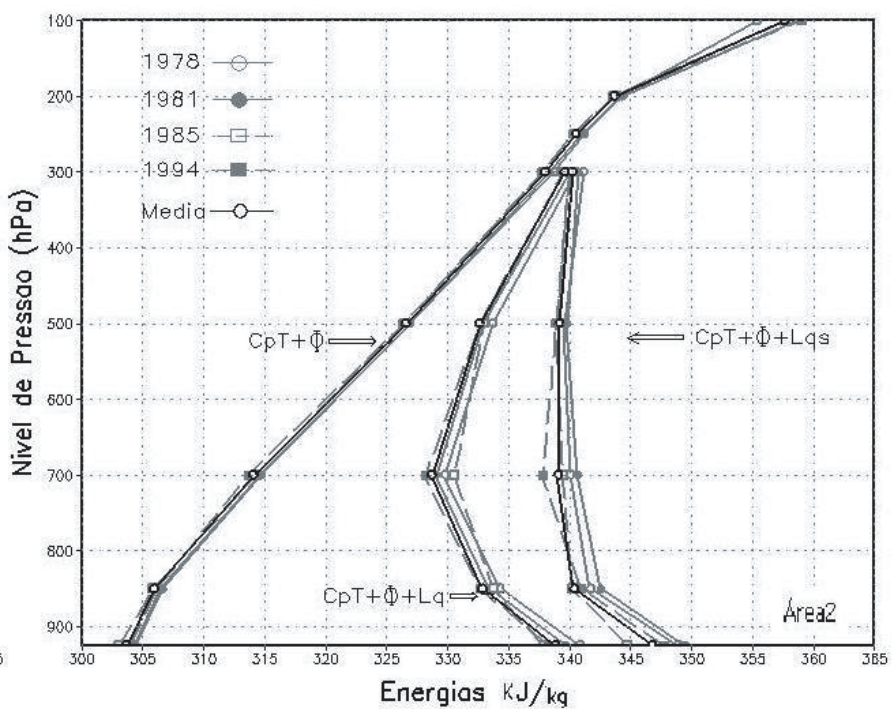

(b)

Figura 6 - Perfis verticais das energias estáticas seca, úmida e saturada média do trimestre fevereiro-abril para as áreas a) 1 e b) 2 durante episódios de Dipolo positivo (linhas continuas) e Dipolo negativo (linhas tracejadas)

maior do NEB. Em geral, foram observadas maiores áreas cobertas de convergências (divergências) de fluxo de energia em baixos e médios níveis (Altos níveis) do que nos anos de El Niño.

Durante os anos de dipolos (Figuras 9 e 10), as variações encontradas foram mais destacadas em baixos níveis. Por exemplo, sobre o Oceano Atlântico Tropical, foi observada a faixa de convergência de energia estática mais ao sul (norte) durante os anos de dipolo negativo (positivo), coerentes com estudos realizados por inúmeros pesquisadores. Souza (1997), durante a fase negativa (positiva) do dipolo, encontrou a zona de convergência dos ventos superficiais deslocados ao sul (ao norte) do equador, assim como o fluxo de umidade. Durante os anos de fase positiva do dipolo (Figura 9), na camada de 925$850 \mathrm{hPa}$, pode ser visualizada convergência no fluxo de energia estática em grande parte da região Norte e NEB, e divergência 
no litoral leste e sul do NEB e SW da região Norte do Brasil. No entanto, durante os episódios opostos, a convergência atingiu o litoral leste do NEB. Nas camadas acima, durante os quatros eventos, a divergência no fluxo de energia estática latente, visualizada em baixos níveis sobre o NEB, atinge o norte e leste da região. No entanto, a energia estática seca apresentou o comportamento semelhante apenas no ano de 1978 (Figura 9a) e 1994 (Figura 10b).

Em níveis médios (500-300hPa) do ano de 1985, foi visualizada uma área de convergência no fluxo de energia estática seca sobre a região Amazônica e norte do NEB. Em 1994, este comportamento atingiu grande parte da região Norte
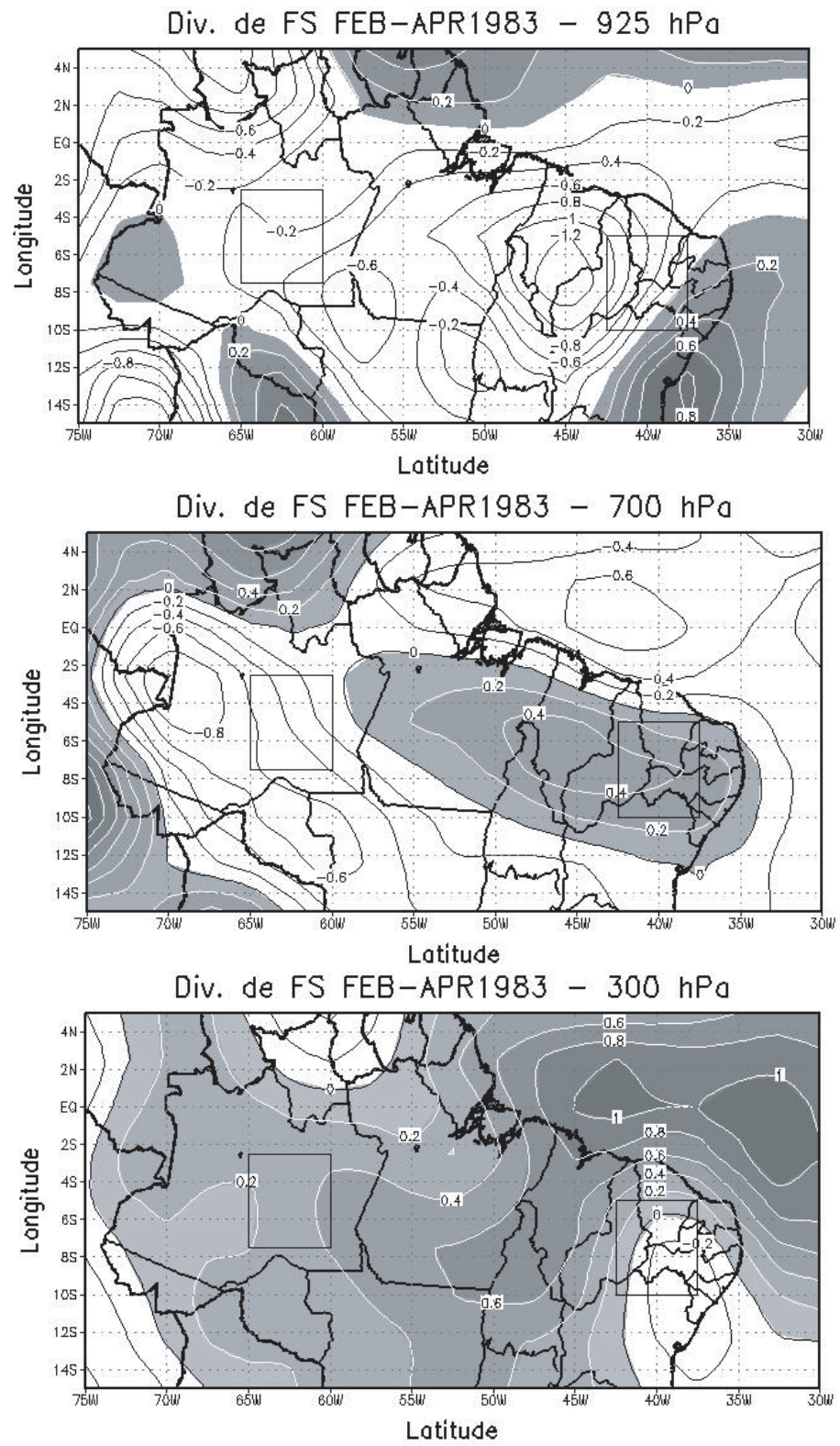

e NEB, exceto o Estado de Roraima, norte da Amazonas e NW do Pará que apresentaram comportamentos opostos. Na região norte do NEB, também foram encontradas na energiaestática latente, convergências no fluxo de energia, porém com maiores áreas nos anos de 1978 (Figura 9a) e 1985 (Figura 10a). Na região Norte, em geral, as áreas sobre sul do Amazonas foram as que apresentaram convergência no fluxo de estática energia latente durante os anos de dipolos.

A forte convergência no fluxo de energia estática seca em baixos níveis e por continuidade de massa, divergência nos altos níveis foi visualizada sobre o Norte e Nordeste do Brasil, durante todos os anos selecionados.
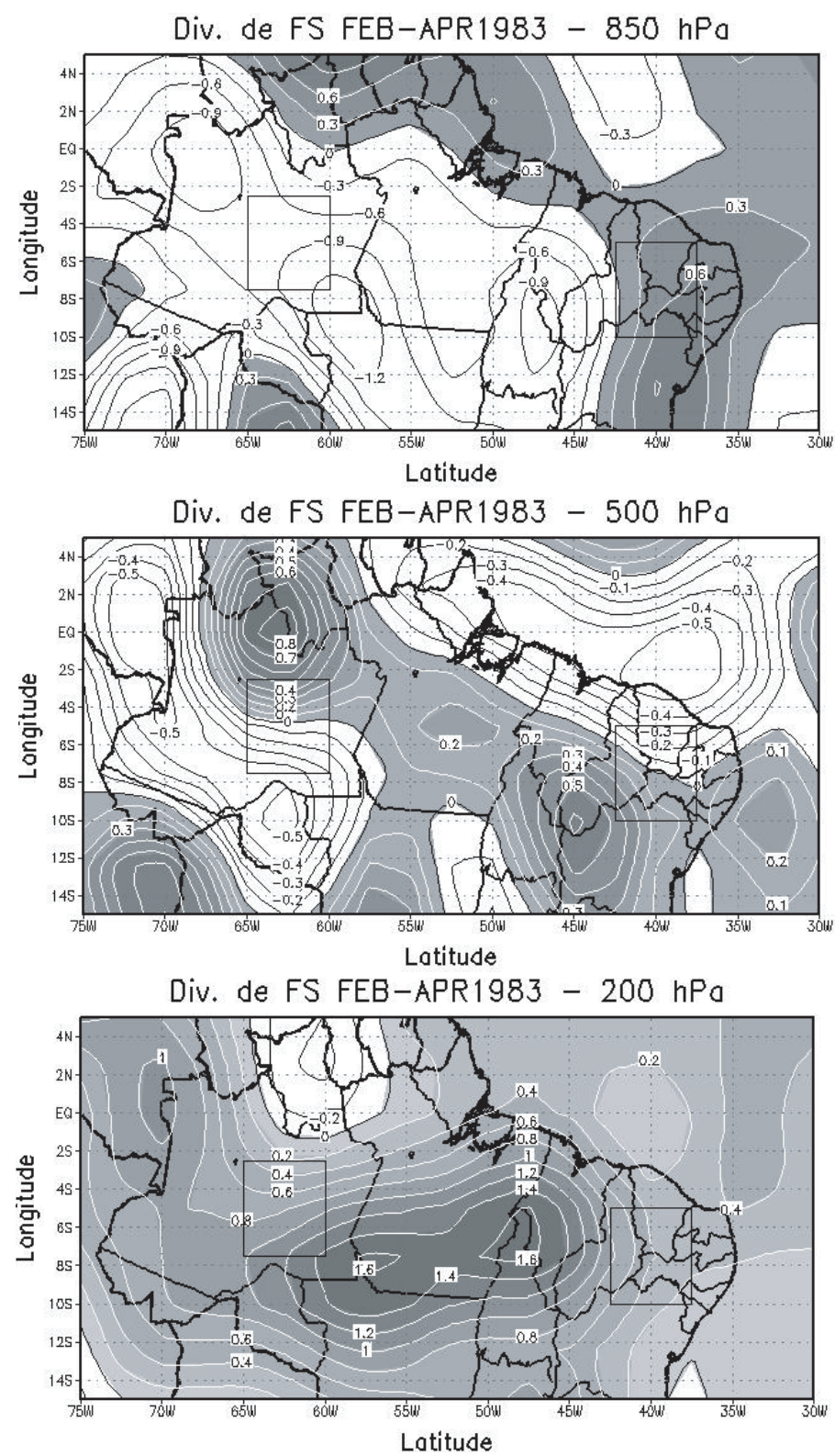

Figura 7a - Média trimestral (fevereiro a abril) da divergência do Fluxo das Energias Estáticas Seca [(cpT+Ф)] e Latente [(Lvq) ] (kJ/m²s) nas camadas 925-850; 850-700; 700-500; 500-300; 300-200 e 200-100 hPa para o ano de El Niño de 1983. As áreas sombreadas (claras) representam divergências (convergências) 

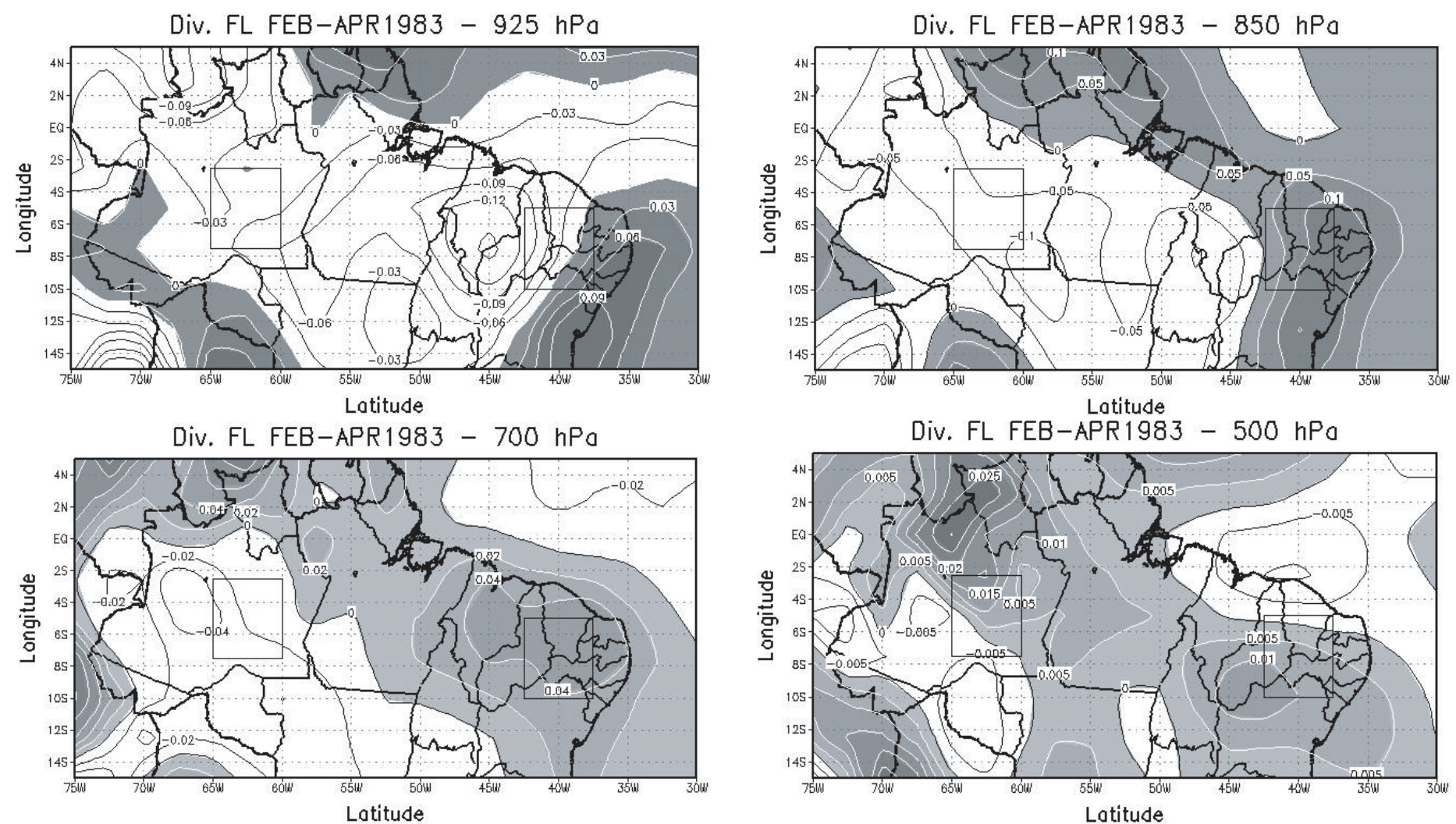

Figura 7a - (Continuação)
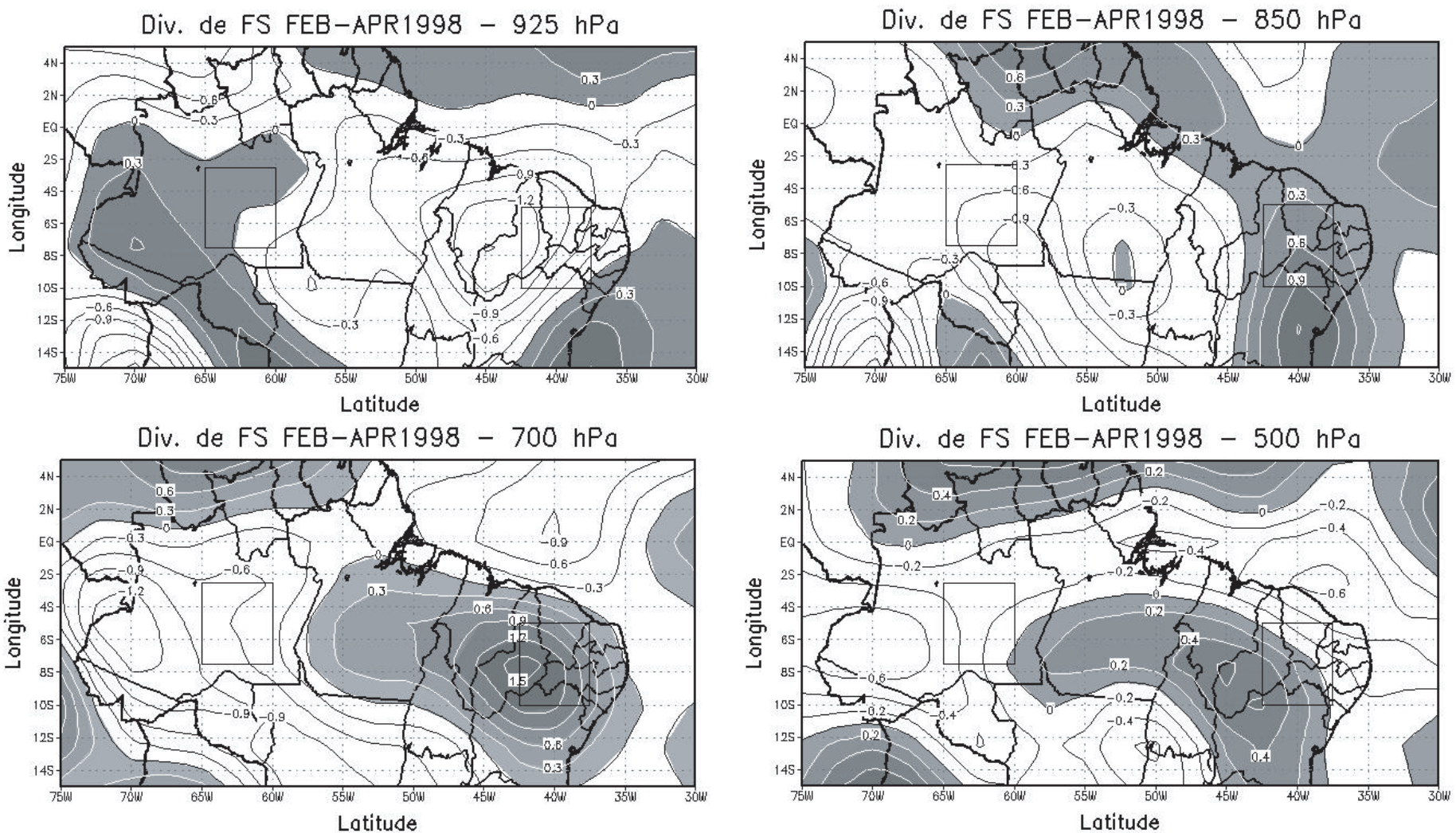

Figura 7b - Idem a Fig. 7a, porém para o ano de El Nino de 1998 

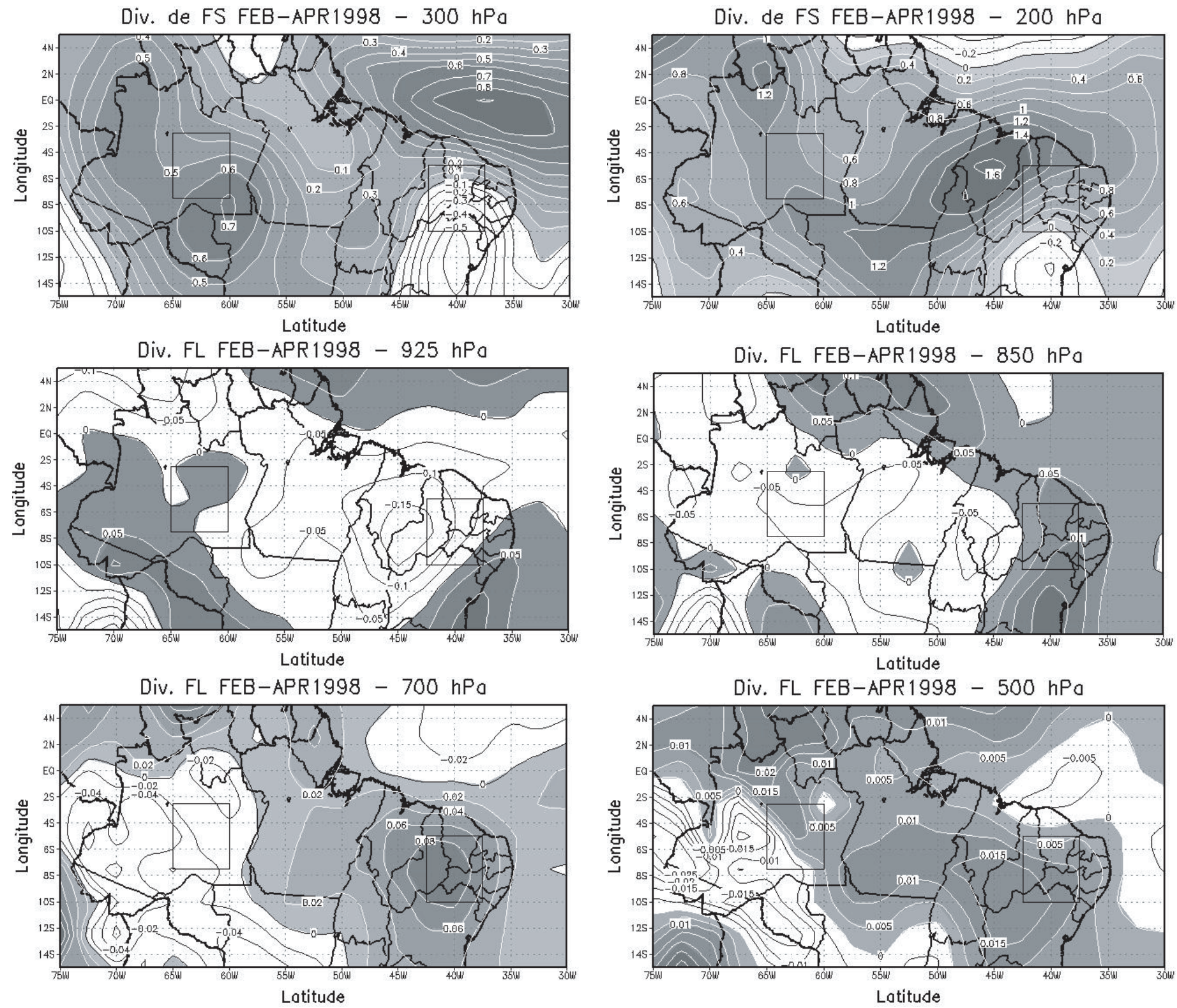

Figura $7 b-($ Continuação $)$
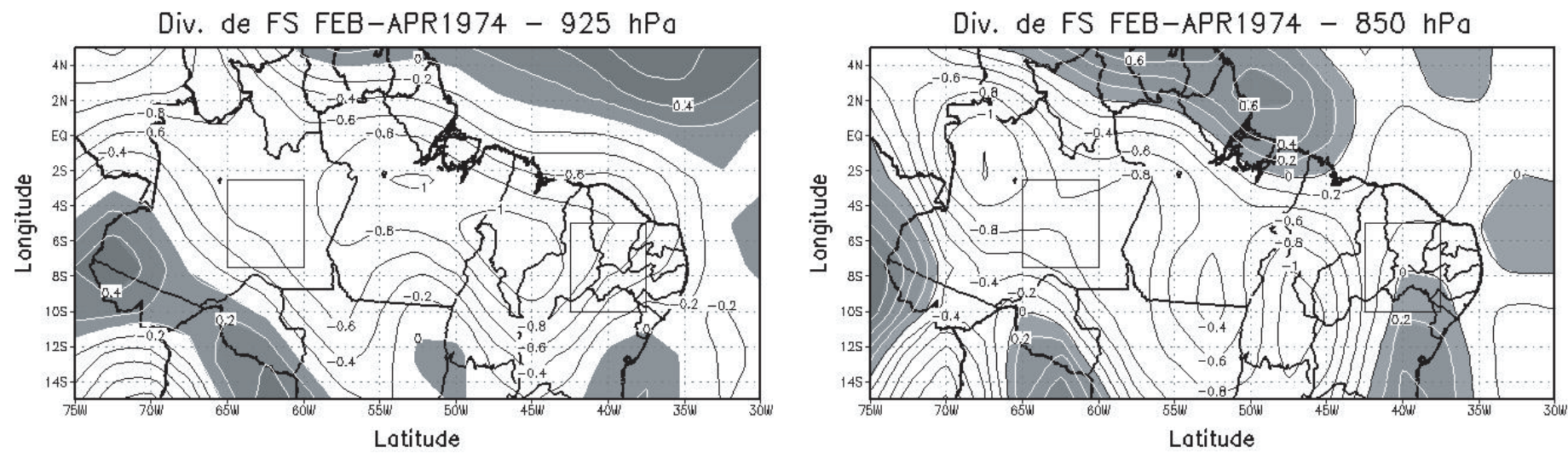

Figura 8a - Idem a Fig. 7a, porém para o ano de La Niña de 1974 

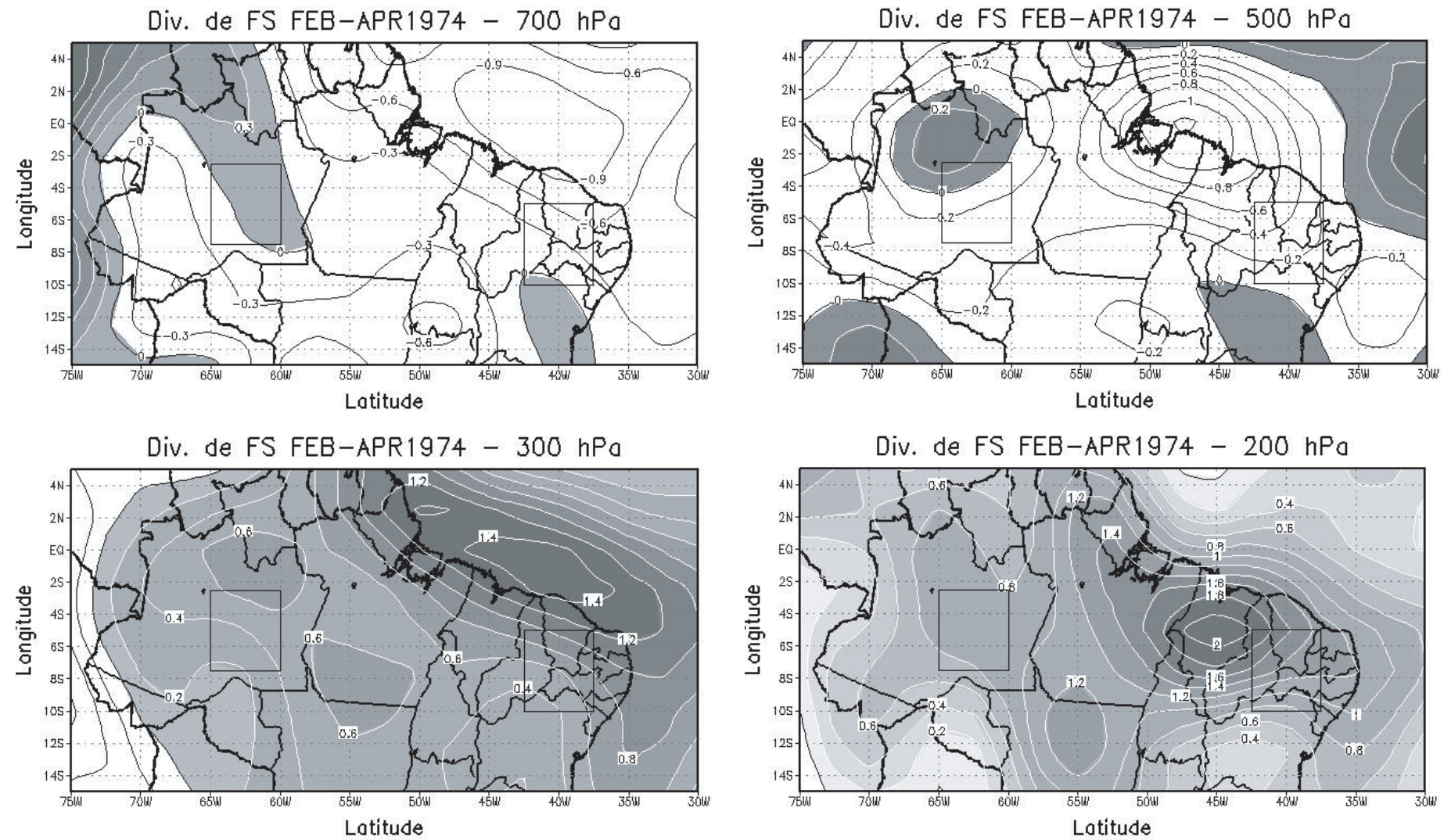

Div. FL FEB-APR1974 - 925 hPa
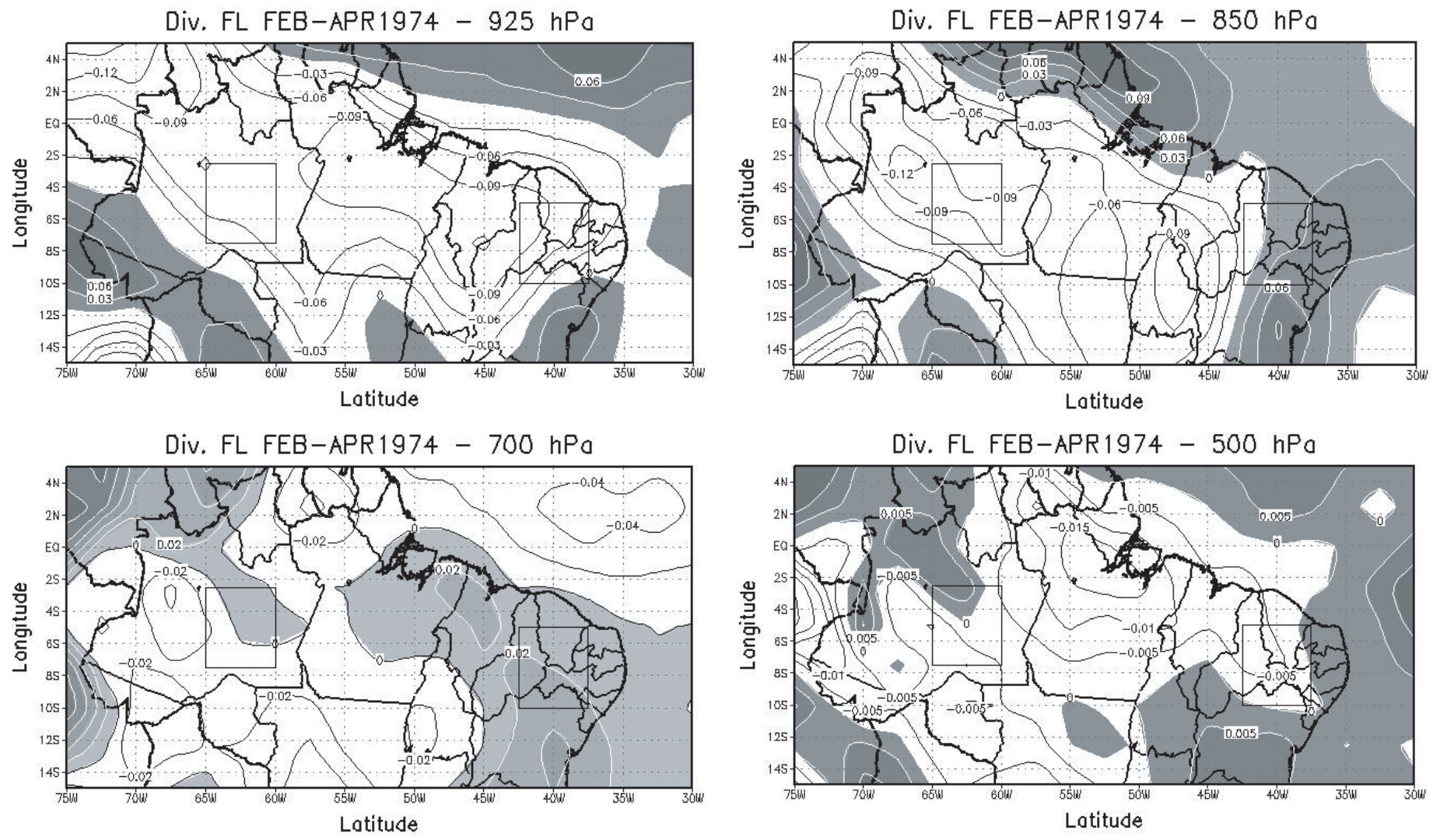

Figura 8a - (Continuação) 

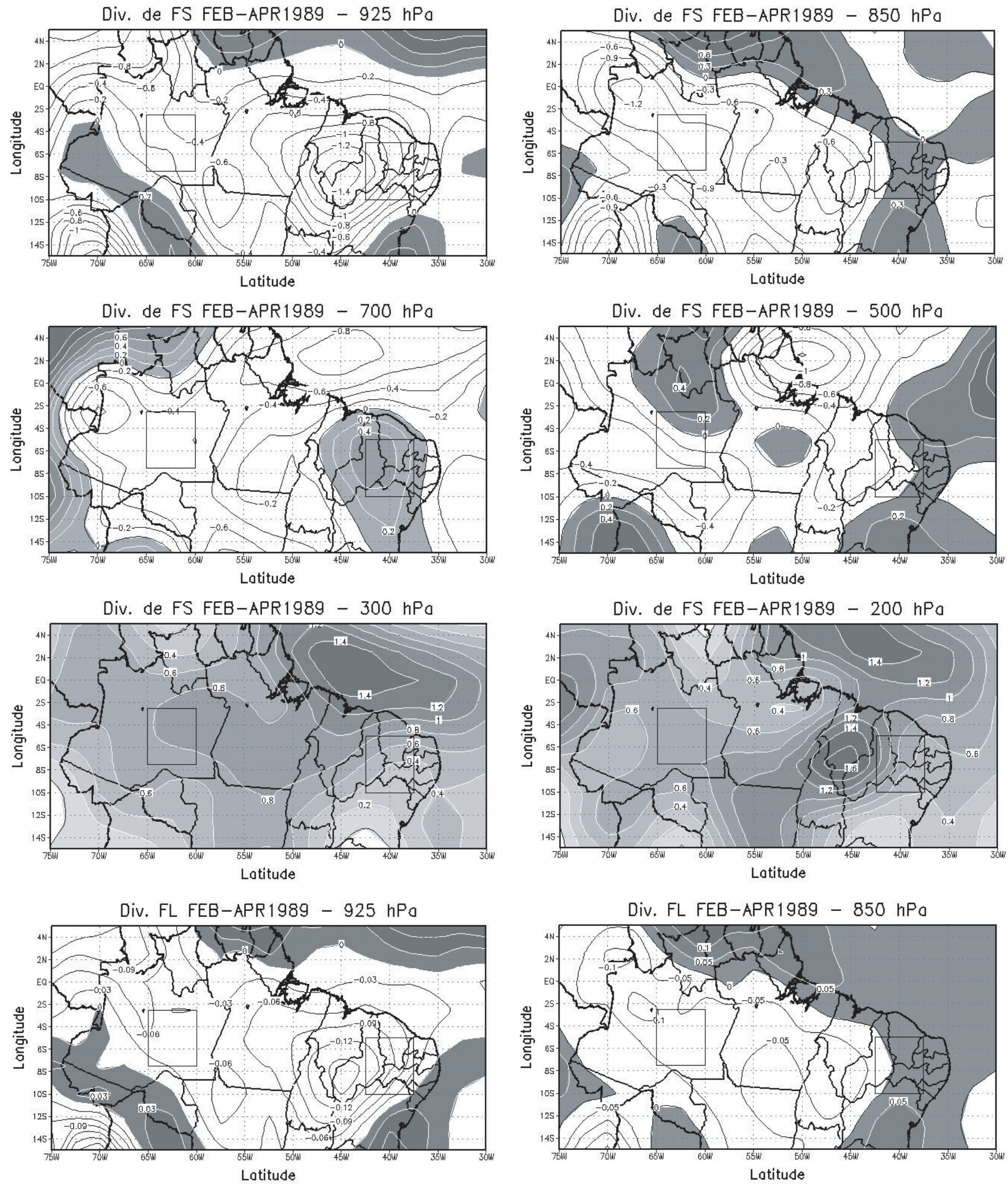

Figura 8b - Idem a Fig. 7a, porém para o ano de La Niña de 1989 

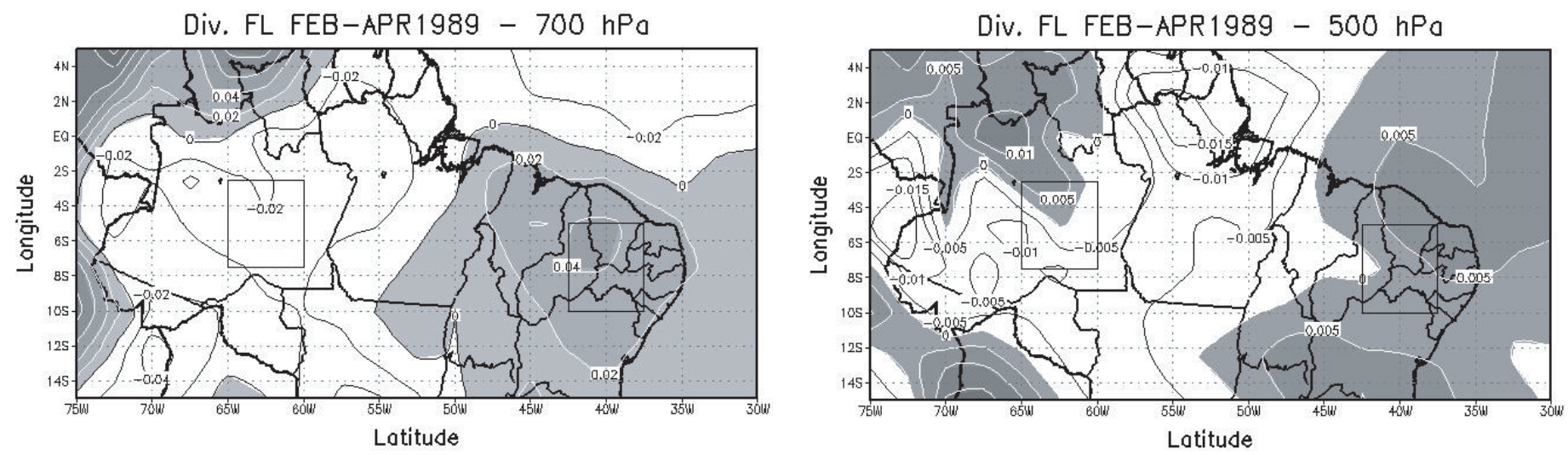

Figura 8b - (Continuação)
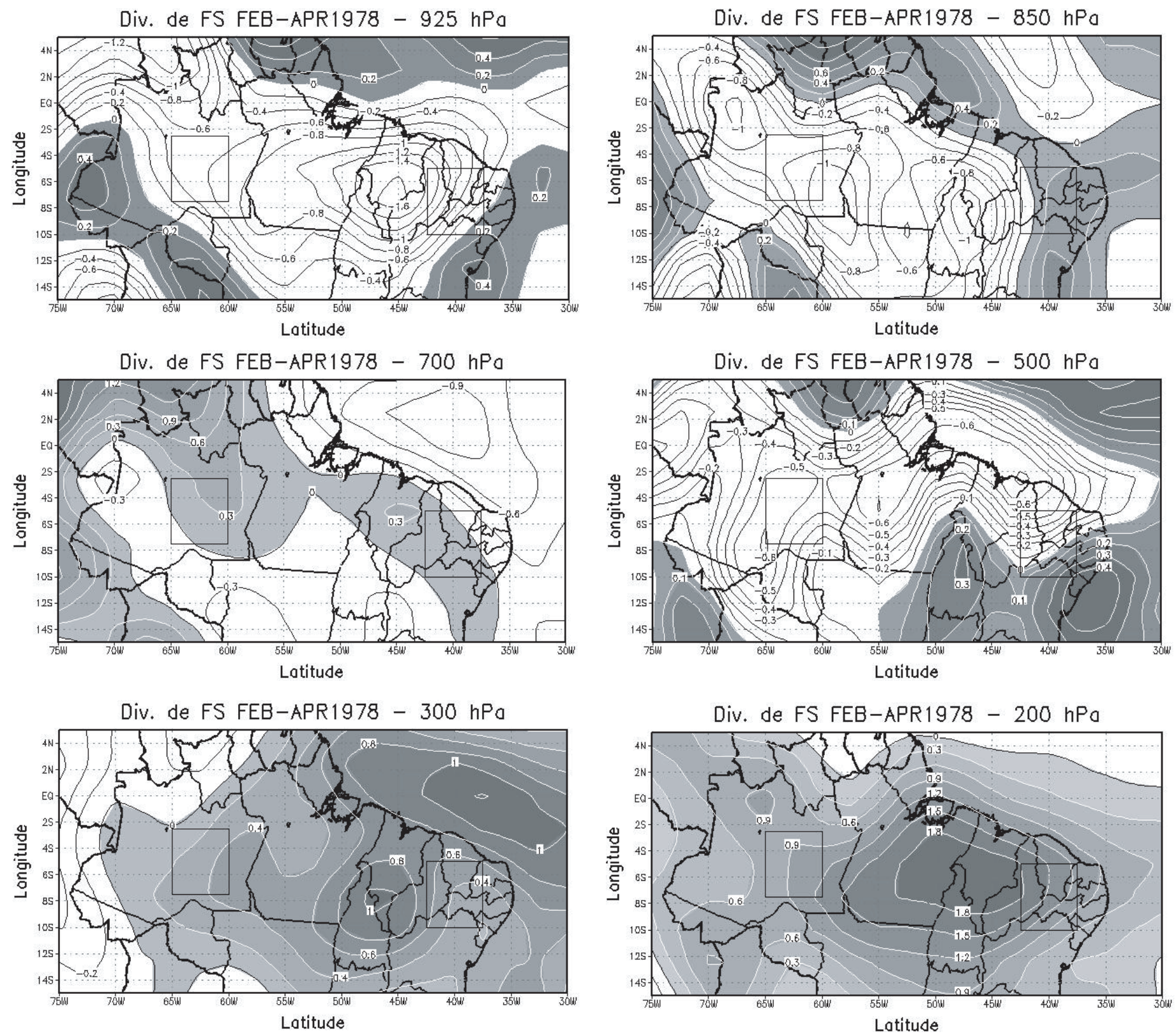

Figura 9a - Idem a Fig. 7a, porém para o ano de Dipolo positivo de 1978 

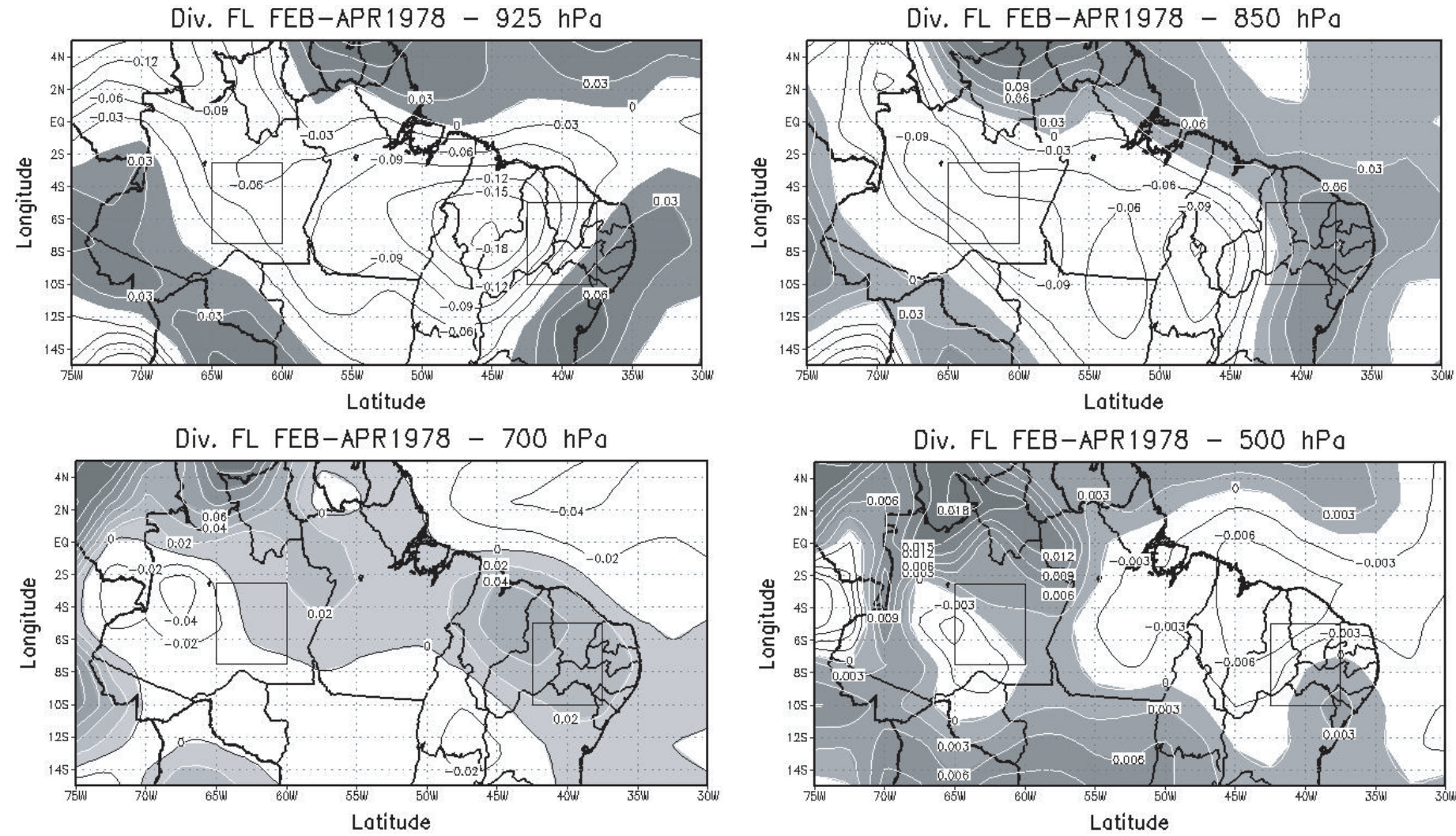

Figura 9a - (Continuação)
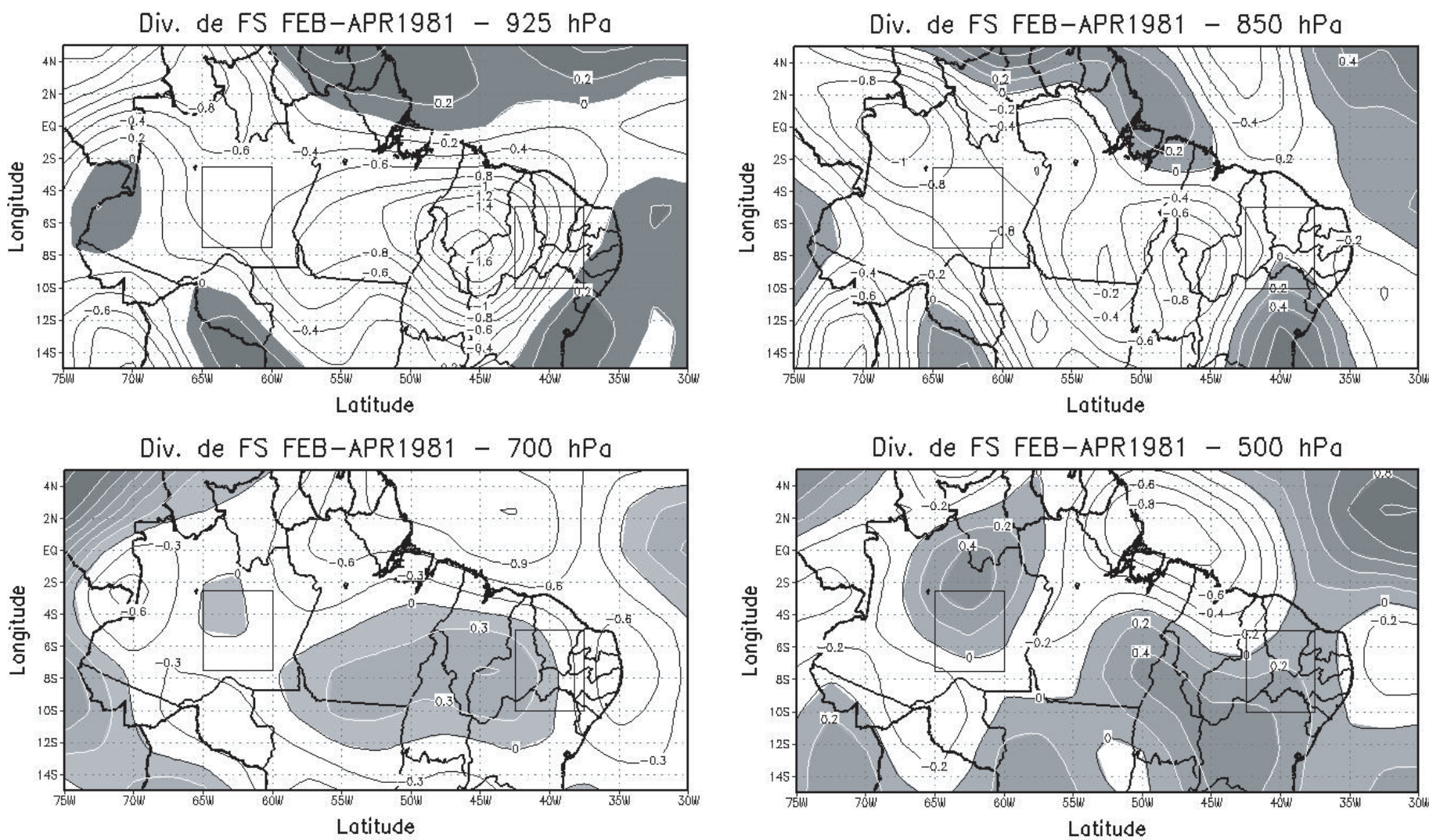

Figura 9b - Idem a Fig. 7a, porém para o ano de Dipolo positivo de 1981 

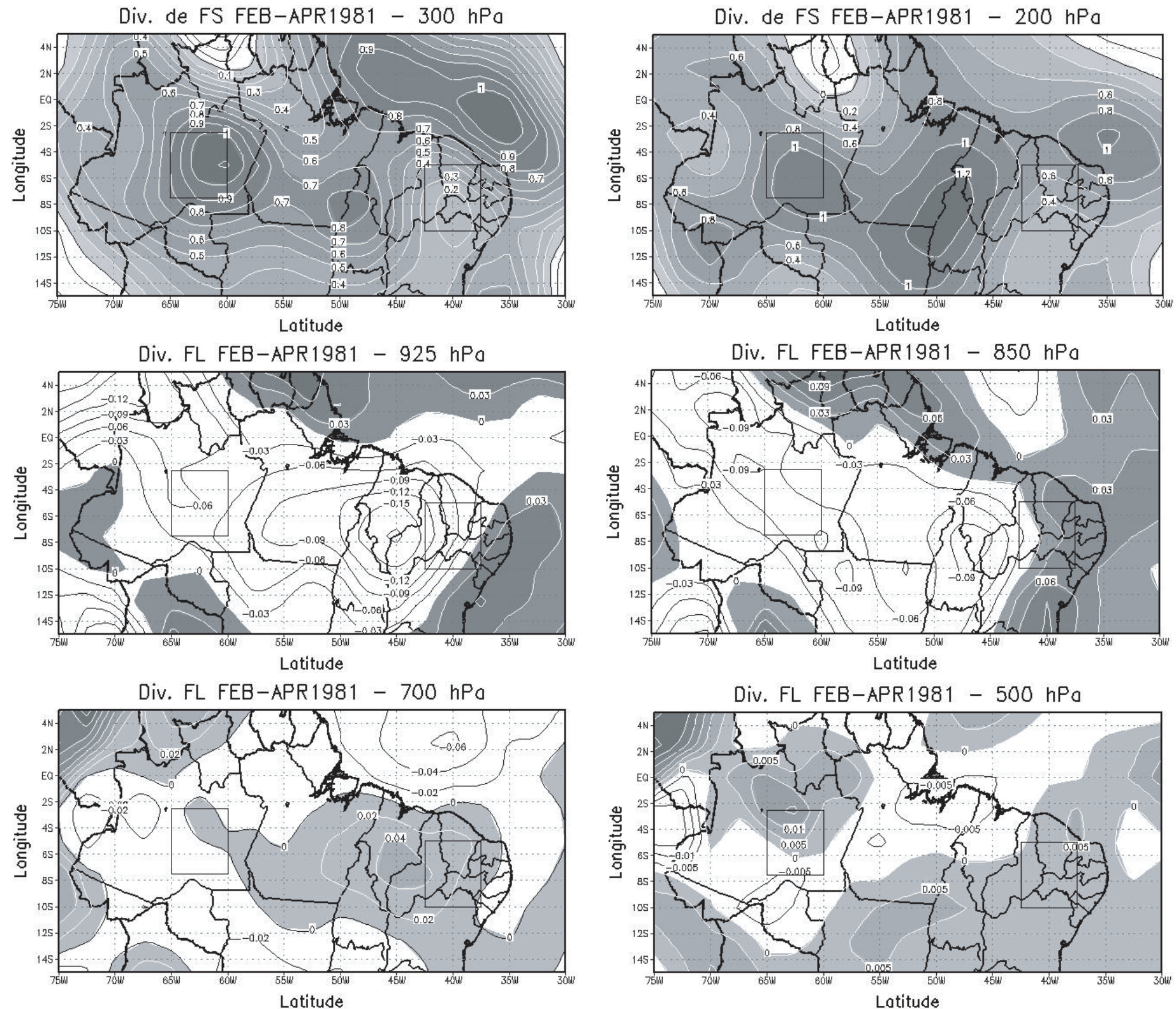

Figura 9b - (Continuação)
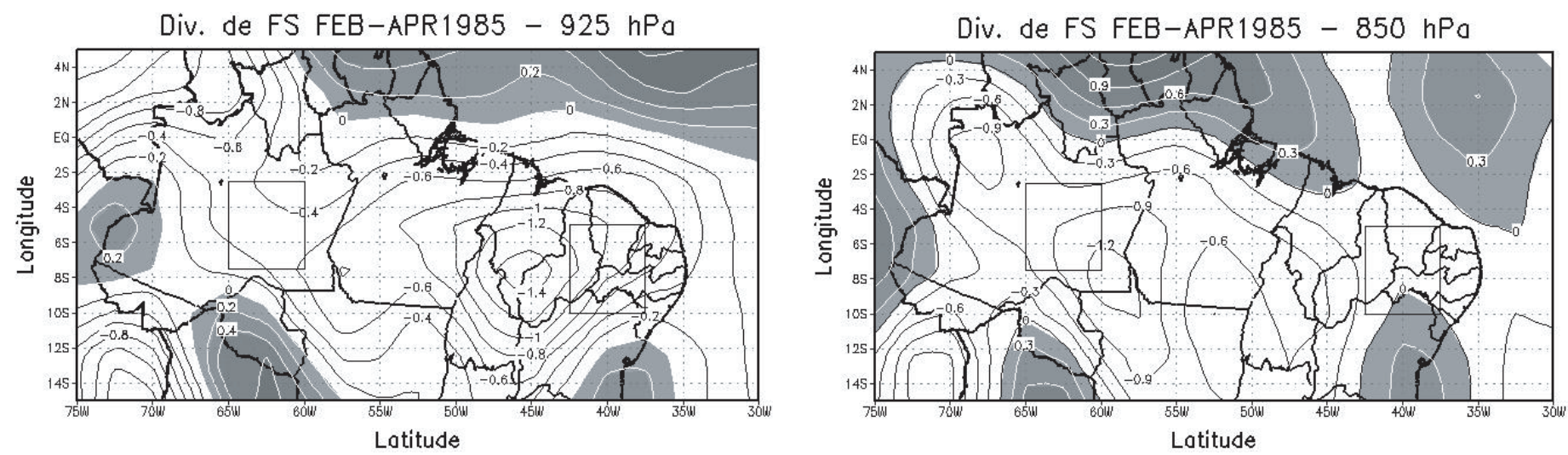

Figura 10a - Idem a Fig. 7a, porém para o ano de Dipolo negativo de 1985 

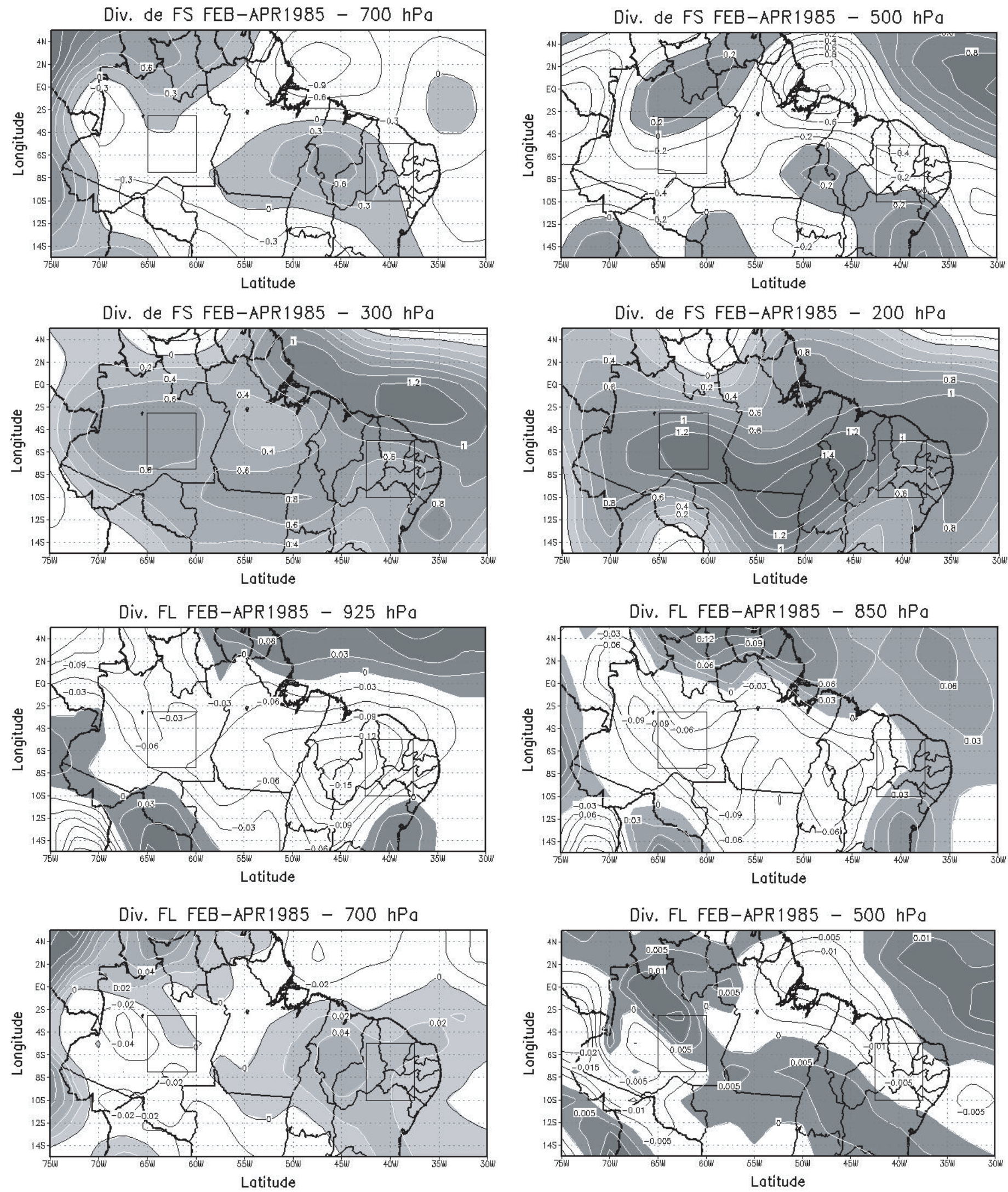

Figura 10a - (Continuação) 

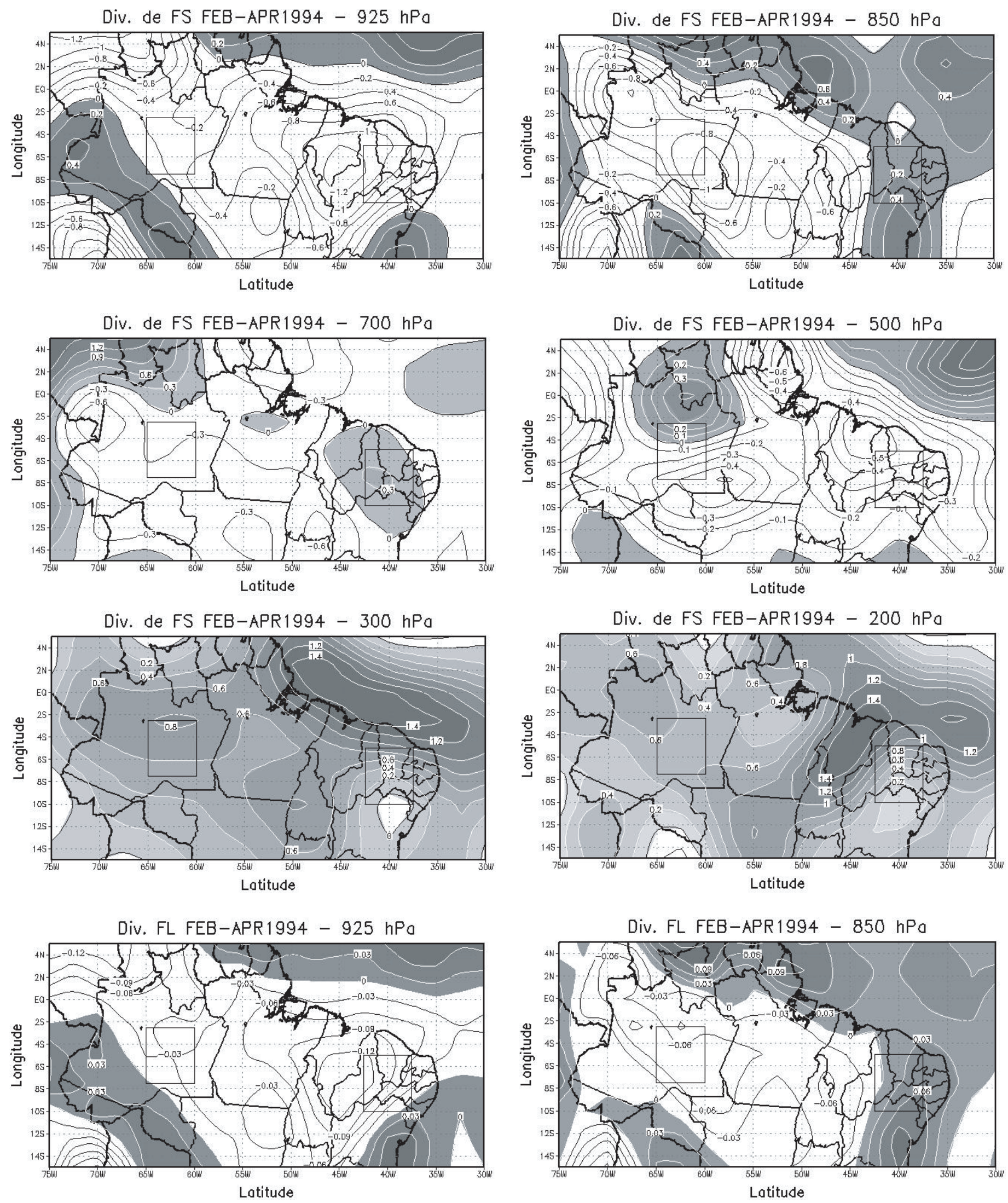

Figura 10b - Idem a Fig. 7a, porém para o ano de Dipolo negativo de 1994 

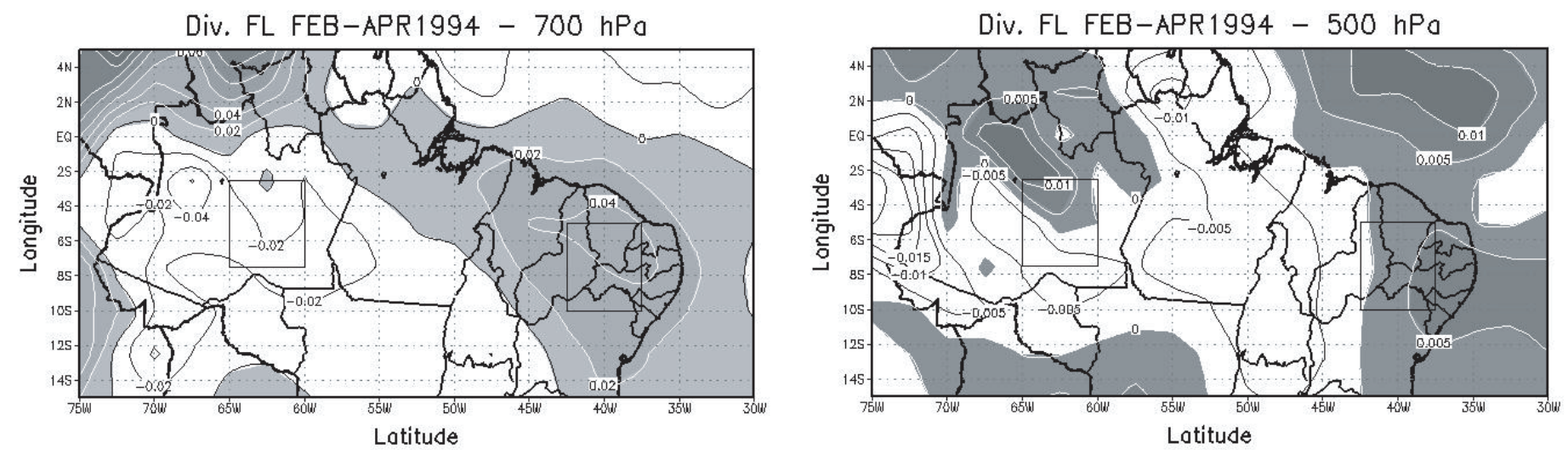

Figura 10b - (Continuação)

\subsection{Fluxo de Energia Estática}

Os resultados encontrados dos fluxos de energias estáticas (a) seca, (b) latente e (c) úmida para as áreas 1 e 2, nos anos de El Niños, La Niña, dipolos positivos e negativos são observados nas Tabelas 2 e 3, respectivamente, e estão expressos em $10^{11} \mathrm{~kJ} \cdot \mathrm{s}^{-1}$.

Teoricamente sabe-se que o termo exportação está associado à divergência e importação à convergência. Os fluxos de energia estática seca (sensível) e latente têm efeitos importantes sobre a atmosfera, trazendo umidade e calor para a mesma, essenciais para a organização da convecção e das precipitações (Tao 1991). Em períodos chuvosos, qualquer que seja a escala de tempo, em geral, há convergência (divergência) de vapor d'água em baixo e médio níveis (alto nível), e durante períodos seco há divergência (convergência) (Marques et al., 1982).

Para o ano de 1983, o fluxo de energia estática seca média (fevereiro a abril) na área 1 apresentou importação nas camadas $925-850 \mathrm{hPa}, 850-700 \mathrm{hPa}, 700-500 \mathrm{hPa}$ e $500-$ $300 \mathrm{hPa}$, exportação nas camadas $300-200 \mathrm{hPa}$ e $200-100 \mathrm{hPa}$ e importação de $-1,171 \times 10^{11} \mathrm{~kJ} . \mathrm{s}^{-1}$ na integração vertical. No outro episódio de El Niño, 1998, o comportamento do fluxo de energia se apresentou semelhante, com uma mudança apenas na camada de $925-850 \mathrm{hPa}$, na qual apresentou exportação e o valor da importação na integral vertical foi de $-0,264 \times 10^{11} \mathrm{~kJ} \cdot \mathrm{s}^{-1}$.

O fluxo de energia estática latente (Tabela $2 b$ ) para os dois eventos de El Niños, apresentou importação nas camadas abaixo de $500 \mathrm{hPa}$ (exceto no ano de 1998 na camada de $925-850 \mathrm{hPa}$ uma exportação foi visualizada) e exportação na camada de 500$300 \mathrm{hPa}$. Acima da camada de $500-300 \mathrm{hPa}$, os valores de fluxos de energia estática latente se anulam, devido ausência de umidade na atmosfera. Quanto à integral vertical do fluxo de energia latente, o valor encontrado de importação foi de $-0,330 \times 10^{11} \mathrm{~kJ} . \mathrm{s}^{-}$ ${ }^{1}$ para o ano de $1983 \mathrm{e} \mathrm{de}-0,181 \times 10^{11} \mathrm{~kJ} . \mathrm{s}^{-1}$ para o ano de 1998.

A energia estática úmida (Tabela 2c) apresentou fluxo

importado em baixos níveis até a camada de 500-300hPa no ano de 1983 e acima desta observou-se exportação. Em 1998, houve exportação de fluxo de energia nas camadas $925-850 \mathrm{hPa}, 300-$ 200hPa e 200-100hPa, e importação nas camadas intermediárias. O fluxo importado na integral vertical foi de $-1,499 \times 10^{11} \mathrm{~kJ} . \mathrm{s}^{-1} \mathrm{e}$ $-0,445 \times 10^{11} \mathrm{~kJ} . \mathrm{s}^{-1}$ para o ano de 1983 e 1998, respectivamente.

Durante os anos de La Niña, observou-se fluxo de importação de energia estática seca nas camadas de $925-850 \mathrm{hPa}$ a 500-300hPa (apenas em 1974 a camada de 700-500hPa apresentou exportação) e exportação no restante das camadas. Os valores encontrados na integração vertical nos dois episódios foram de $-0,718 \times 10^{11} \mathrm{~kJ} . \mathrm{s}^{-1}$ em 1974 e de $-1,331 \times 10^{11} \mathrm{~kJ} . \mathrm{s}^{-1}$ em 1989.

O fluxo de energia latente apresentou importação em todas as camadas durante os dois episódios de La Niña, e a integral vertical visualizada foi de importação com valores iguais a $-0,488 \times 10^{11} \mathrm{~kJ} . \mathrm{s}^{-1} \mathrm{em} 1974 \mathrm{e}-0,437 \times 10^{11} \mathrm{~kJ} . \mathrm{s}^{-1} \mathrm{em}$ 1989.

A energia estática úmida nos anos 1974 e 1989 apresentou importação de seus fluxos nas camadas $925-850 \mathrm{hPa}$ a 500 $300 \mathrm{hPa}$, exportação nas camadas a partir do nível de pressão de $300 \mathrm{hPa}$, e importações de $-1,206 \times 10^{11} \mathrm{~kJ}^{-\mathrm{s}^{-1}} \mathrm{e}-1,768 \times 10^{11} \mathrm{~kJ} . \mathrm{s}^{-1}$ nas integrações verticais dos dois anos, respectivamente.

Para os anos de dipolos positivos tem-se que em 1978, o fluxo de energia estática seca apresentou importação para as duas primeiras camadas, $925-850 \mathrm{hPa}$ e $850-700 \mathrm{hPa}$, exportação na camada de 700-500hPa e voltou a ser observada importação de fluxo na camada de 500-300hPa. Nas camadas acima, 300$200 \mathrm{hPa}$ e $200-100 \mathrm{hPa}$, foram observadas exportações. No outro evento, 1981, nas três primeiras camadas $(925-850 \mathrm{hPa}$, $850-700 \mathrm{hPa}$ e $700-500 \mathrm{hPa}$ ) observaram-se importações, nas demais, exportações.

A importação de energia estática seca tornou-se mais profunda nos eventos de dipolos negativos, ou seja, foram visualizadas importação nas quatros primeiras camadas (925$850 \mathrm{hPa}$ a $500-300 \mathrm{hPa}$ ) e apenas as duas últimas, $300-200 \mathrm{hPa}$ e 200-100hPa, exportação. As integrações verticais dos fluxos 
de energias estática seca durante os episódios de dipolo, apresentaram importação com valores iguais a $-1,193 \times 10^{11} \mathrm{~kJ} . \mathrm{s}^{-1}$ e $-0,534 \times 10^{11} \mathrm{~kJ} . \mathrm{s}^{-1}$ nos anos de $1978($ dipolo + ) e 1994 (dipolo -) e exportação de $2,284 \times 10^{11} \mathrm{~kJ} . \mathrm{s}^{-1}$ e de $0,906 \times 10^{11} \mathrm{~kJ} . \mathrm{s}^{-1}$ nos anos de 1981 (dipolo +) e 1985 (dipolo -), respectivamente.

Nos anos de dipolos positivos, observou-se importação no fluxo da energia latente nas camadas $925-850 \mathrm{hPa}$ e $850-700 \mathrm{hPa}$, sendo que, em 1978, na camada 700-500hPa, houve exportação, voltando a ser visualizada baixa importação na camada acima. Em geral, observou-se importação nos baixos níveis (camadas inferiores a $700 \mathrm{hPa}$ ) e exportação em níveis médios.

Para o ano de 1985 (dipolo -), o comportamento assemelha-se ao observado em 1981. Em 1994, foi observada importação em todas as camadas. Na integração em toda vertical, os quatros eventos apresentam importação de $-0,422 \times 10^{11} \mathrm{~kJ} . \mathrm{s}^{-1}$; $-0,372 \times 10^{11} \mathrm{~kJ} . \mathrm{s}^{-1} ;-0,405 \times 10^{11} \mathrm{~kJ} . \mathrm{s}^{-1} \mathrm{e}-0,332 \times 10^{11} \mathrm{~kJ} . \mathrm{s}^{-1}$.

Durante os anos de dipolos, os fluxos de energia estática úmida apresentaram importação em baixos níveis nas camadas 925-850hPa e 850-700hPa, somente acima dessas camadas houve características distintas na atmosfera entre os anos de dipolos. Por exemplo, no ano de 1978, a camada logo acima apresentou exportação, porém a importação volta a ser visualizada nas duas últimas camadas, $300-200 \mathrm{hPa}$ e $200-100 \mathrm{hPa}$. Em 1981, a importação atinge mais uma camada (700-500hPa).

Os anos de dipolos negativos foram os que apresentaram a atmosfera com importação mais profunda atingindo até a camada de 500-300hPa, porém, quando se determinou o módulo da integral vertical, os valores foram menores nas camadas de 300-200 e 200-100hPa e houve exportação. Foram visualizados nas integrações verticais, importações nos anos de 1978 e 1994 com valores iguais a $-1,614 \times 10^{11} \mathrm{~kJ}_{\text {s }}{ }^{-1}$ e $-0,867 \times 10^{11} \mathrm{~kJ} . \mathrm{s}^{-1} \mathrm{e}$ exportação em 1981 e 1985 de $1,913 \times 10^{11} \mathrm{~kJ}^{-s^{-1}}$ e $0,500 \times 10^{11}$ $\mathrm{kJ} . \mathrm{s}^{-1}$, respectivamente.

Os resultados da Tabela 2 mostraram que a atmosfera na área 1, durante todos os episódios estudados dos anos de El Niño, La Nina e dipolos positivos e negativos, apesar das diferentes características e intensidade entre os fenômenos, o comportamento apresentado foi de um sumidouro de vapor d'água.

Na área 2 (Tabela 3), localizada sobre a região semi-árida, durante os episódios quentes do Pacífico, 1983 e 1998, houve importação de energia estática seca nas camadas de $925-850 \mathrm{hPa}$ e a $300-200 \mathrm{hPa}$. As camadas de $850-700 \mathrm{hPa}$ a $500-300 \mathrm{hPa}$ e a de 200-100hPa apresentaram exportação. A integração vertical apresentou exportação em 1983 de 2,201x10 $0^{11}$ kJ.s ${ }^{-1}$ e em 1998 de $4,049 \times 10^{11} \mathrm{~kJ} . \mathrm{s}^{-1}$.

Nos anos de La Niña, os fluxos de energia estática seca no ano de 1989 também apresentaram importação em duas camadas, a de 925-850hPa, como visualizado nos anos de El Nino, e a de 500-300hPa camada esta abaixo da encontrada nos anos de El Nino. Em 1974, as quatros primeiras camadas apresentaram importações, e as duas últimas localizadas em altos níveis, exportações. A integração vertical apresentou exportação de $2,046 \times 10^{11} \mathrm{~kJ} . \mathrm{s}^{-1}$ em 1974 e de $2,274 \times 10^{11} \mathrm{~kJ} . \mathrm{s}^{-1}$ em 1989.

Os fluxos de energia latente apresentaram durante os anos de El Niño e La Niña importações apenas na camada de 925-850hPa. Em 1974, a camada de 500-300hPa apresentou importação, diferenciando-se dos outros eventos. A integração vertical apresentou exportação (importação) nos anos de 1983 e 1998 (1974 e 1989) com valores de $0,340 \times 10^{11} \mathrm{~kJ}_{\text {. }} \mathrm{s}^{-1}$ e de $0,248 \times 10^{11} \mathrm{~kJ} . \mathrm{s}^{-1}\left(-0,074 \times 10^{11} \mathrm{~kJ} . \mathrm{s}^{-1}\right.$ e $\left.-0,064 \times 10^{11} \mathrm{~kJ} . \mathrm{s}^{-1}\right)$, segundo os valores acima encontrados, a atmosfera da área 2 nos anos de El Niño (La Niña) comportou-se como fonte (sumidouro) de vapor d'água.

Quanto ao fluxo de energia estática úmida, foi visualizado nos anos de El Niños importação de energia nas camadas, 925$850 \mathrm{hPa}$ e $300-200 \mathrm{hPa}$. Já as camadas de $850-700 \mathrm{hPa}$ a 500 $300 \mathrm{hPa}$ e a de $200-100 \mathrm{hPa}$ apresentaram exportação. O ano de La Niña de 1989 foi semelhante ao ano de El Niño, apresentando duas camadas apenas com importação, a de 925-850hPa e a de 500-300hPa. No episódio de 1974, nas camadas abaixo (acima) de $300 \mathrm{hPa}$ foram identificadas importação (exportação) de fluxo de energia estática úmida. Na integração vertical, foram observadas exportações de 2,540x $10^{11} \mathrm{~kJ} . \mathrm{s}^{-1} ; 4,296 \times 10^{11} \mathrm{~kJ} . \mathrm{s}^{-1}$; $1,973 \times 10^{11} \mathrm{~kJ} . \mathrm{s}^{-1}$ e $2,211 \times 10^{11} \mathrm{~kJ} \mathrm{~kg}^{-1}$ para os anos de 1983,1998 , 1974 e 1989, respectivamente.

O episódio de dipolo positivo de 1978 apresentou no fluxo de energia estática seca importação nas camadas de 925-850hPa e 500-300hPa, e exportação nas camadas de 850$700 \mathrm{hPa}$ e $700-500 \mathrm{hPa}$. Resultado semelhantemente foi obtido no ano de fase negativa de 1994, porém com valores diferentes. No ano de 1981, importações nas camadas compreendidas em baixos níveis $(925-850 \mathrm{hPa}, 850-700 \mathrm{hPa}$ e $700-50 \mathrm{hPa})$ e exportação em altos níveis foram obtidas. No evento negativo de dipolo de 1985, foram visualizadas importação no fluxo de energia na camada de $925-850 \mathrm{hPa}, 850-700 \mathrm{hPa}$ e $500-300 \mathrm{hPa}$, e exportação na camada de $700-500 \mathrm{hPa}$ e em altos níveis.

A integração vertical da energia latente apresentou durante os dipolos exportação de $0,070 \times 10^{11} \mathrm{~kJ} . \mathrm{s}^{-1}$ apenas em 1978, e importação em 1981, 1985 e 1994, com valores iguais a $-0,043 \times 10^{11} \mathrm{~kJ} . \mathrm{s}^{-1} ;-0,188 \times 10^{11} \mathrm{~kJ}_{\text {s }}{ }^{-1}$ e $-0,005 \times 10^{11}$ $\mathrm{kJ} . \mathrm{s}^{-1}$, respectivamente. Isto significa que a atmosfera sobre o Nordeste do Brasil, na área selecionada, comportou-se como fonte de vapor d'água apenas em 1978. No outro evento de 1981, assim como, nos dipolos negativos, o comportamento da atmosfera foi de sumidouro de vapor d'água.

Quanto à energia estática úmida, nos anos de 1978 e 1994, foram visualizadas importações em duas camadas, em baixos (925-850hPa) e médios níveis $(500-300 \mathrm{hPa})$, e exportação nas camadas compreendidas entre 850 e $500 \mathrm{hPa}$ e altos níveis. Em 
1981, as duas primeiras camadas, $925-850 \mathrm{hPa}$ e $850-700 \mathrm{hPa}$ apresentaram importações e as camadas acima exportação.

No ano de 1985, o fluxo de energia estática úmida apresentou importações (exportações) nas camadas 925$850 \mathrm{hPa}, 850-700 \mathrm{hPa}$ e $500-300 \mathrm{hPa}(700-500 \mathrm{hPa}, 300-$ $200 \mathrm{hPa}$ e $200-100 \mathrm{hPa}$ ). Nos quatros episódios de dipolos foram observadas exportações na integração vertical com valores iguais a $3,860 \times 10^{11} \mathrm{~kJ}^{-1} \mathrm{~s}^{-1} 0,857 \times 10^{11} \mathrm{~kJ} . \mathrm{s}^{-1}$; $1,200 \times 10^{11} \mathrm{~kJ} . \mathrm{s}^{-1}$ e $0,463 \times 10^{11} \mathrm{~kJ}^{-1}{ }^{-1}$, respectivamente.
Na região do NEB, foi visualizado na integração vertical da energia latente valores de sinal positivo para os anos de El Niño e dipolo positivo e de sinal negativo para La Niña e fase negativa do dipolo. Portanto, exportações de vapor d'água foram visualizadas durante os episódios conhecidos como inibidores, e importação durante os episódios causadores de precipitação. Porém, o ano de 1981 (Dipolo +) apresentou importação. Entretanto, vale ressaltar que não foi aplicado ajuste de massa, o que certamente, daria resultados mais fundamentados.

Tabela 2 - Fluxo trimestral médio de fevereiro a abril $\left(10^{11} \mathrm{~kJ} / \mathrm{s}\right)$ na área 1 (Norte do Brasil): (a) fluxo de $\left(\mathrm{C}_{\mathrm{p}} \mathrm{T}+\phi\right)$, (b) fluxo de $\left(\mathrm{L}_{\mathrm{v}} \mathrm{q}\right)$ e (c) fluxo de $\left(\mathrm{C}_{\mathrm{p}} \mathrm{T}+\phi+\mathrm{L}_{\mathrm{v}} \mathrm{q}\right)$. Valores em negrito representam importação de energia

(a)

\begin{tabular}{c|cccccccc}
\hline \multirow{2}{*}{ Pressão (hPa) } & \multicolumn{2}{|c}{ El Niño } & \multicolumn{2}{c}{ La Niña } & \multicolumn{2}{c}{ Dipolo (+) } & \multicolumn{2}{c}{ Dipolo (-) } \\
\cline { 2 - 9 } & 1983 & 1998 & 1974 & 1989 & 1978 & 1981 & 1985 & 1994 \\
\hline $925-850$ & $\mathbf{- 0 , 7 4 8}$ & 0,096 & $\mathbf{- 1 , 9 2 0}$ & $\mathbf{- 1 , 1 5 5}$ & $\mathbf{- 1 , 5 6 6}$ & $\mathbf{- 1 , 5 8 0}$ & $\mathbf{- 1 , 2 9 6}$ & $\mathbf{- 0 , 6 6 8}$ \\
$850-700$ & $\mathbf{- 2 , 4 9 8}$ & $\mathbf{- 1 , 8 5 6}$ & $\mathbf{- 2 , 5 0 0}$ & $\mathbf{- 2 , 7 6 4}$ & $\mathbf{- 2 , 3 5 1}$ & $\mathbf{- 2 , 1 1 6}$ & $\mathbf{- 2 , 5 8 3}$ & $\mathbf{- 2 , 3 6 1}$ \\
$700-500$ & $\mathbf{- 1 , 2 0 1}$ & $\mathbf{- 1 , 9 0 9}$ & 0,009 & $\mathbf{- 1 , 5 7 0}$ & 0,496 & $\mathbf{- 0 , 2 6 2}$ & $\mathbf{- 0 , 2 5 4}$ & $\mathbf{- 0 , 9 6 5}$ \\
$500-300$ & $\mathbf{- 0 , 0 6 6}$ & $\mathbf{- 0 , 8 8 8}$ & $\mathbf{- 0 , 3 6 9}$ & $\mathbf{- 0 , 4 8 0}$ & $\mathbf{- 1 , 4 3 3}$ & 0,413 & $\mathbf{- 0 , 4 1 7}$ & $\mathbf{- 0 , 3 2 0}$ \\
$300-200$ & 0,936 & 1,587 & 1,341 & 2,479 & 0,882 & 2,843 & 2,005 & 2,040 \\
$200-100$ & 2,406 & 2,706 & 2,721 & 2,159 & 2,779 & 2,986 & 3,450 & 1,740 \\
\hline $925-100$ & $\mathbf{- 1 , 1 7 1}$ & $\mathbf{- 0 , 2 6 4}$ & $\mathbf{- 0 , 7 1 8}$ & $\mathbf{- 1 , 3 3 1}$ & $\mathbf{- 1 , 1 9 3}$ & 2,284 & 0,905 & $\mathbf{- 0 , 5 3 4}$ \\
\hline
\end{tabular}

(b)

\begin{tabular}{c|cccccccc}
\hline \multirow{2}{*}{ Pressão (hPa) } & \multicolumn{2}{|c}{ El Niño } & \multicolumn{2}{c}{ La Niña } & \multicolumn{2}{c}{ Dipolo (+) } & \multicolumn{2}{c}{ Dipolo (-) } \\
\cline { 2 - 9 } & 1983 & 1998 & 1974 & 1989 & 1978 & 1981 & 1985 & 1994 \\
\hline $925-850$ & $\mathbf{- 0 , 0 8 3}$ & 0,006 & $\mathbf{- 0 , 2 0 8}$ & $\mathbf{- 0 , 1 2 6}$ & $\mathbf{- 0 , 1 7 1}$ & $\mathbf{- 0 , 1 7 0}$ & $\mathbf{- 0 , 1 4 7}$ & $\mathbf{- 0 , 0 7 6}$ \\
$850-700$ & $\mathbf{- 0 , 1 9 4}$ & $\mathbf{- 0 , 1 2 7}$ & $\mathbf{- 0 , 2 5 7}$ & $\mathbf{- 0 , 2 2 7}$ & $\mathbf{- 0 , 2 5 2}$ & $\mathbf{- 0 , 1 9 4}$ & $\mathbf{- 0 , 2 3 1}$ & $\mathbf{- 0 , 1 9 4}$ \\
$700-500$ & $\mathbf{- 0 , 0 6 7}$ & $\mathbf{- 0 , 0 6 4}$ & $\mathbf{- 0 , 0 1 4}$ & $\mathbf{- 0 , 0 7 4}$ & 0,002 & $\mathbf{- 0 , 0 1 7}$ & $\mathbf{- 0 , 0 3 3}$ & $\mathbf{- 0 , 0 6 0}$ \\
$500-300$ & 0,014 & 0,004 & $\mathbf{- 0 , 0 0 9}$ & $\mathbf{- 0 , 0 1 0}$ & $\mathbf{- 0 , 0 0 1}$ & 0,009 & 0,006 & $\mathbf{- 0 , 0 0 2}$ \\
$300-200$ & - & - & - & - & - & - & - & - \\
$200-100$ & - & - & - & - & - & - & - & - \\
\hline $925-100$ & $\mathbf{- 0 , 3 3 0}$ & $\mathbf{- 0 , 1 8 1}$ & $\mathbf{- 0 , 4 8 8}$ & $\mathbf{- 0 , 4 3 7}$ & $\mathbf{- 0 , 4 2 2}$ & $\mathbf{- 0 , 3 7 2}$ & $\mathbf{- 0 , 4 0 5}$ & $\mathbf{- 0 , 3 3 2}$
\end{tabular}

(c)

\begin{tabular}{c|cccccccc}
\hline \multirow{2}{*}{ Pressão (hPa) } & \multicolumn{2}{|c}{ E1 Niño } & \multicolumn{2}{c}{ La Niña } & \multicolumn{2}{c}{ Dipolo (+) } & \multicolumn{2}{c}{ Dipolo (-) } \\
\cline { 2 - 9 } & 1983 & 1998 & 1974 & 1989 & 1978 & 1981 & 1985 & 1994 \\
\hline $925-850$ & $\mathbf{- 0 , 8 3 1}$ & 0,102 & $\mathbf{- 2 , 1 2 8}$ & $\mathbf{- 1 , 2 8 1}$ & $\mathbf{- 1 , 7 3 7}$ & $\mathbf{- 1 , 7 5 0}$ & $\mathbf{- 1 , 4 4 3}$ & $\mathbf{- 0 , 7 4 4}$ \\
$850-700$ & $\mathbf{- 2 , 6 9 1}$ & $\mathbf{- 1 , 9 8 3}$ & $\mathbf{- 2 , 7 5 7}$ & $\mathbf{- 2 , 9 9 1}$ & $\mathbf{- 2 , 6 0 3}$ & $\mathbf{- 2 , 3 1 0}$ & $\mathbf{- 2 , 8 1 4}$ & $\mathbf{- 2 , 5 5 6}$ \\
$700-500$ & $\mathbf{- 1 , 2 6 7}$ & $\mathbf{- 1 , 9 7 3}$ & $\mathbf{- 0 , 0 0 5}$ & $\mathbf{- 1 , 6 4 4}$ & 0,498 & $\mathbf{- 0 , 2 7 9}$ & $\mathbf{- 0 , 2 8 7}$ & $\mathbf{- 1 , 0 2 5}$ \\
$500-300$ & $\mathbf{- 0 , 0 5 2}$ & $\mathbf{- 0 , 8 8 4}$ & $\mathbf{- 0 , 3 7 8}$ & $\mathbf{- 0 , 4 9 0}$ & $\mathbf{- 1 , 4 3 3}$ & 0,423 & $\mathbf{- 0 , 4 1 1}$ & $\mathbf{- 0 , 3 2 2}$ \\
$300-200$ & 0,936 & 1,587 & 1,341 & 2,479 & 0,882 & 2,843 & 2,005 & 2,040 \\
$200-100$ & 2,406 & 2,706 & 2,721 & 2,159 & 2,779 & 2,986 & 3,450 & 1,740 \\
\hline $925-100$ & $\mathbf{- 1 , 4 9 9}$ & $\mathbf{- 0 , 4 4 5}$ & $\mathbf{- 1 , 2 0 6}$ & $\mathbf{- 1 , 7 6 8}$ & $\mathbf{- 1 , 6 1 4}$ & 1,913 & 0,500 & $\mathbf{- 0 , 8 6 7}$ \\
\hline
\end{tabular}




\section{CONCLUSÕES}

A investigação dos aspectos da circulação atmosférica de grande escala, a partir da fonte aparente de calor e do sumidouro aparente de umidade nas regiões norte e nordeste do Brasil, e suas relações com a variabilidade da temperatura da superfície do mar nos oceanos Atlântico e Pacífico Tropicais, permitiram encontrar algumas características importantes sobre o comportamento das anomalias de energia estática em anos de eventos extremos.
A região Amazônica, por está localizada numa área de floresta tropical úmida, apresenta atmosfera mais úmida do que o Nordeste semi-árido. No entanto, o Oceano Atlântico abastece a região do NEB de energia latente, fazendo com que o comportamento do perfil vertical das duas atmosferas seja aproximadamente igual.

Durante os episódios quentes (frios), El Niño e dipolo positivo (La Niña e dipolo negativo), a atmosfera das áreas $1 \mathrm{e}$ 2 apresentou-se menos (mais) úmida. A energia estática seca, apesar de não apresentar variações de destaque, apresentou

Tabela 3 - Fluxo trimestral médio de fevereiro a abril $\left(10^{11} \mathrm{~kJ} / \mathrm{s}\right.$ ) na área 2 (Nordeste do Brasil): (a) fluxo de $\mathrm{C}_{\mathrm{p}} \mathrm{T}+\phi$, (b) fluxo de ( $\left.\mathrm{L}_{\mathrm{v}} \mathrm{Q}\right)$ e (c) fluxo de $\left(\mathrm{C}_{\mathrm{p}} \mathrm{T}+\phi+\mathrm{L}_{\mathrm{v}} \mathrm{q}\right)$. Valores em negrito representam importação de energia

(a)

\begin{tabular}{c|cccccccc}
\hline \multirow{2}{*}{ Pressão (hPa) } & \multicolumn{2}{|c}{ E1 Niño } & \multicolumn{2}{c}{ La Niña } & \multicolumn{2}{c}{ Dipolo (+) } & \multicolumn{2}{c}{ Dipolo (-) } \\
\cline { 2 - 9 } & 1983 & 1998 & 1974 & 1989 & 1978 & 1981 & 1985 & 1994 \\
\hline $925-850$ & $\mathbf{- 1 , 1 9 2}$ & $\mathbf{- 2 , 3 9 3}$ & $\mathbf{- 1 , 9 4 0}$ & $\mathbf{- 2 , 5 1 8}$ & $\mathbf{- 1 , 8 0 7}$ & $\mathbf{- 1 , 8 4 5}$ & $\mathbf{- 2 , 5 2 9}$ & $\mathbf{- 2 , 4 1 2}$ \\
$850-700$ & 1,187 & 1,468 & $\mathbf{- 0 , 3 7 8}$ & 0,069 & 0,359 & $\mathbf{- 0 , 2 8 5}$ & $\mathbf{- 0 , 3 0 1}$ & 0,414 \\
$700-500$ & 0,895 & 3,018 & $\mathbf{- 0 , 9 5 2}$ & 1,023 & 0,227 & $\mathbf{- 0 , 0 3 4}$ & 0,227 & 0,515 \\
$500-300$ & 0,033 & 0,224 & $\mathbf{- 0 , 8 0 8}$ & $\mathbf{- 0 , 1 5 8}$ & $\mathbf{- 0 , 3 5 0}$ & 0,504 & $\mathbf{- 0 , 5 0 9}$ & $\mathbf{- 0 , 9 9 6}$ \\
$300-200$ & $\mathbf{- 0 , 0 5 2}$ & $\mathbf{- 0 , 3 6 6}$ & 2,190 & 1,558 & 1,439 & 0,937 & 1,882 & 1,239 \\
$200-100$ & 1,330 & 2,098 & 3,934 & 2,300 & 3,922 & 1,624 & 2,618 & 1,707 \\
\hline $925-100$ & 2,201 & 4,049 & 2,046 & 2,274 & 3,790 & 0,901 & 1,388 & 0,467 \\
\hline
\end{tabular}

(b)

\begin{tabular}{c|cccccccc}
\hline \multirow{2}{*}{ Pressão (hPa) } & \multicolumn{2}{c}{ E1 Niño } & \multicolumn{2}{c}{ La Niña } & \multicolumn{2}{c}{ Dipolo (+) } & \multicolumn{2}{c}{ Dipolo (-) } \\
\cline { 2 - 9 } & 1983 & 1998 & 1974 & 1989 & 1978 & 1981 & 1985 & 1994 \\
\hline $925-850$ & $\mathbf{- 0 , 0 7 2}$ & $\mathbf{- 0 , 2 1 9}$ & $\mathbf{- 0 , 1 8 1}$ & $\mathbf{- 0 , 2 3 5}$ & $\mathbf{- 0 , 1 6 1}$ & $\mathbf{- 0 , 1 6 9}$ & $\mathbf{- 0 , 2 5 1}$ & $\mathbf{- 0 , 2 2 2}$ \\
$850-700$ & 0,257 & 0,203 & 0,054 & 0,051 & 0,139 & 0,056 & 0,000 & 0,092 \\
$700-500$ & 0,139 & 0,232 & 0,061 & 0,109 & 0,099 & 0,064 & 0,074 & 0,116 \\
$500-300$ & 0,016 & 0,032 & $\mathbf{- 0 , 0 0 8}$ & 0,011 & $\mathbf{- 0 , 0 0 7}$ & 0,006 & $\mathbf{- 0 , 0 1 1}$ & 0,009 \\
$300-200$ & - & - & - & - & - & - & - & - \\
$200-100$ & - & - & - & - & - & - & - & - \\
\hline $925-100$ & 0,340 & 0,248 & $\mathbf{- 0 , 0 7 4}$ & $\mathbf{- 0 , 0 6 4}$ & 0,070 & $\mathbf{- 0 , 0 4 3}$ & $\mathbf{- 0 , 1 8 8}$ & $\mathbf{- 0 , 0 0 5}$ \\
\hline & & & & $(\mathbf{c})$ & & & & \\
\hline \multirow{2}{*}{ Pressão (hPa) } & El Niño & La Niña & Dipolo $(+)$ & Dipolo (-) \\
\cline { 2 - 9 } & 1983 & 1998 & 1974 & $\mathbf{1 9 8 9}$ & 1978 & 1981 & $\mathbf{1} 985$ & 1994 \\
\hline $925-850$ & $\mathbf{- 1 , 2 6 4}$ & $\mathbf{- 2 , 6 1 2}$ & $\mathbf{- 2 , 1 2 1}$ & $\mathbf{- 2 , 7 5 3}$ & $\mathbf{- 1 , 9 6 8}$ & $\mathbf{- 2 , 0 1 5}$ & $\mathbf{- 2 , 7 8 0}$ & $\mathbf{- 2 , 6 3 4}$ \\
$850-700$ & 1,444 & 1,671 & $\mathbf{- 0 , 3 2 4}$ & 0,121 & 0,498 & $\mathbf{- 0 , 2 2 9}$ & $\mathbf{- 0 , 3 0 1}$ & 0,507 \\
$700-500$ & 1,033 & 3,250 & $\mathbf{- 0 , 8 9 0}$ & 1,132 & 0,326 & 0,030 & 0,301 & 0,631 \\
$500-300$ & 0,049 & 0,255 & $\mathbf{- 0 , 8 1 6}$ & $\mathbf{- 0 , 1 4 7}$ & $\mathbf{- 0 , 3 5 7}$ & 0,510 & $\mathbf{- 0 , 5 2 0}$ & $\mathbf{- 0 , 9 8 7}$ \\
$300-200$ & $\mathbf{- 0 , 0 5 2}$ & $\mathbf{- 0 , 3 6 6}$ & $\mathbf{2 , 1 9 0}$ & 1,558 & 1,439 & 0,937 & 1,882 & 1,239 \\
$200-100$ & 1,330 & 2,098 & $\mathbf{3 , 9 3 4}$ & 2,300 & 3,922 & 1,624 & 2,618 & 1,707 \\
\hline $925-100$ & 2,540 & 4,296 & 1,973 & $\mathbf{2 , 2 1 1}$ & $\mathbf{3 , 8 6 0}$ & 0,857 & 1,200 & 0,463 \\
\hline
\end{tabular}


variações acima (abaixo) da média mais significativas durante os anos de El Niño (La Niña) do que durante os anos de dipolo positivo (dipolos negativos).

Foram observadas menores (maiores) áreas de convergência de energia estática em baixos níveis e divergência em altos níveis sobre as regiões Norte e Nordeste do Brasil durante os anos de El Niño (La Niña). Durante a fase positiva (negativa) dos Dipolos, a faixa de convergência de energia estática sobre o Oceano Atlântico foi observada mais ao norte (ao sul).

O comportamento da região Amazônica foi de um sumidouro de vapor d'água, apesar dos episódios de El Niño, La Nina e dipolos positivos e negativos, com suas diferentes características e intensidade, modularem o período chuvoso da região, intensificando ou desintensificando a convecção. Na região do NEB, a atmosfera se comportou como uma fonte aparente de vapor d'água durante os anos de El Niño e dipolo positivo e sumidouro aparente de umidade para os anos de La Niña e fase negativa do dipolo. Portanto, exportações de vapor d'água foram encontradas durante os episódios conhecidos como inibidores, e importações durante os episódios causadores de precipitação.

A análise média trimestral, a não realização do ajuste de massa e poucos anos de estudos, possivelmente, dissimulou resultados mais consistentes, o que fica como sugestão para trabalhos futuros.

\section{REFERÊNCIAS BIBLIOGRÁFICAS}

BRABO, J. M.; REPELLI, C. A.; MELLO, N. S. A pré-estação chuvosa do setor norte do Nordeste Brasileiro e sua relação com a temperatura dos Oceanos adjacentes. Revista Brasileira de Meteorologia, v. 8, n. 1, p. 22-30, 1993.

CARTON, J. A.; GIESE, B. S.; CAO, X.; MILLER, L. Impact of altimeter, thermistor, and expendable bathy thermograph data on retrospective analyses of the tropical Pacific Ocean. J. Geophys, v. 101, n. 14, p.147-159, 1996.

CAVALCANTI, E. P.; GANDU, A. W.; AZEVEDO, P. V. Transporte e balanço de vapor d'água atmosférico sobre o Nordeste do Brasil. Revista Brasileira de Meteorologia, v. 17, n. 2, p. 207-217, 2002.

CAVALCANTI, Enilson Palmeira. Aspectos Energéticos da Atmosfera sobre o Nordeste do Brasil. 1986. 77f. Dissertação (Mestrado em Meteorologia) - Universidade Federal de Campina Grande, Campina Grande, 1986.

DELECLUSE, P.; SERVAIN, J.; LEVY, C.; LODYC; ARPE, K.; BERGTSSON, L. On the connection between the 1984 Atlantic warm event and the 1982-1983 ENSO. Tellus, v. 46A, p. 448-464, 1994.

Doty, B. The grid analysis and display system - GrADS.
Norwich, UK: University of East Anglia, 1995. 148p.

ENFIELD, D. B.; MAYER, D. A. Tropical Atlantic SST variability and its relation to El Niño-Southern Oscillation. J. Geophys, v. 102, p. 929-945, 1997.

FERREIRA, N. S. Zona de Convergência Intertropical. Boletim do Climanálise Especial - Comemoração dos 10 anos, 1996. Disponível em: http://www.cptec.inpe.br/products/ climanalise/cliesp10a. Acesso em: 22 mar. 2005.

FISCH, G.; MARENGO, J. A.; NOBRE, C. A. Clima da Amazônia. Boletim do Climanálise Especial - Comemoração dos 10 anos, 1996. Disponível em: http://www.cptec.inpe.br/ products/climanalise/cliesp10a. Acesso em: 22 Mar. 2005.

HASTENRATH, S.; HELLER, L. Dynamics of climate hazards in Northeast Brazil. J. Royal Meteorologic Sociedade, v. 103, p. 77-92, 1977.

KALNAY, E.; KANAMITSU, M.; KISTLER, R.; COLLINS W.; DEAVEN, D.; GANDIN, L.; IREDELL, M.; SAHA S.; WHITE G.; WOOLLEN J.; ZHU, Y.; CHELLIAH M.; EBISUZAKI, W.; HIGGINS, W.; JANOWIAK, J.; MO, K. C.; ROPELEWSKI, C.; WANG, J.; LEETMAA, A; REYNOLDS, R.; JENNE, R.; JOSEPH, D. The NCEPNCAR 40-Year Reanalysis Project. Bulletin of the American Meteorological Society, v. 77, n. 3, p. 437-471, 1996.

KISTLER, R.; KALNAY, E.; COLLINS W.; SAHA S.; WHITE G.; WOOLLEN J.; CHELLIAH, M; EBISUZAKI W.; KANAMITSU M.; KOUSKY, V.; DOOL, H. V. D.; JENNE, R.; FIORINO, M. The NCEP-NCAR 50-Year Reanalysis: Monthly Means CD-ROM and Documentation. Bulletin of the American Meteorological Society, v. 82, n. 2, p. 247-267, 2001.

MARENGO, J.; LIEBMANN, B.; KOUSKY, V.; FILIZOLA, N.; WAINER, I. On the onset and end of the rainy season in the Brazilian Amazon Basin. Journal of Climate, v.14, p. 833-852, 2001.

MOURA, A. D.; SHUKLA, J. On the dynamics of the droughts in Northeast Brazil: Observations, theory and numerical experiments with a general circulations model. Journal of the Atmospheric Science, v. 38, n. 12, p. 2653-2673, 1981.

NOBRE, P.; SHUKLA, J. Variations of sea surface temperature, wind stress, and rainfall over the tropical Atlantic and South America. Journal of Climate, v. 9, n.10, p. 2464-2479, 1996.

QUINN, W. H.; ZOPF, D. O.; SHORT, K. S.; YANG KUO, R. T. W. Historical trends and statistics of the Southern Oscillation, El Niño, and Indonesian droughts. Fish. Bull., v. 76, p. 663-678, 1978.

REBOUÇAS, A. C. Água na região Nordeste: Desperdício e escassez. Estudos Avançados, v.11, n 29, p. 127-154, 1997.

REYNOLDS, R.W. A real-time global sea surface temperature 
analysis. Journal of climate, v.1, p. 75-86, 1988.

REYNOLDS, R.W.; MARSICO, D.C. Na improved real - time global sea surface temperature analysis. Journal of climate, v. 6, p. 114-119, 1992.

ROCHA, Edson José Paulino. Balanço de umidade e influência de condições de contorno superficiais sobre a precipitação da Amazônia. 2001. 176f. Tese (Doutorado em Meteorologia) - Instituto Nacional de Pesquisas Espaciais - INPE. São José dos Campos. 2001.

SILVADIAS, P.L. Uma Introdução ao Efeito de Fontes Diabáticas de Calor na Evolução de Sistemas de Tempo. Departamento de Ciências Atmosféricas, Instituto de Astronomia, Geofísica e Ciências Atmosféricas. Universidade de São Paulo, 1999. Disponível em: http://www.master.iag.usp.br/ind.php?inic= 12\&prod=ensino\&pos=2. Acesso em: 22 Nov. 2005.

SILVA MARQUES, V.; RAO, V.B. and MOLION, L.C.B. Interrannual and seasonal variations in the structure and energetics of atmosphere over Northeast Brazil. Tellus, v. 35, n. 2, p. 136-148, 1983.

SOUZA, E.B.; NOBRE, P. Uma revisão do Padrão Dipolo no Atlântico Tropical. Revista Brasileira de Meteorologia, v. 13, n. 1, p. 31-44, 1998.

SOUZA, E. B. GrADS - Fundamentos e Programação Básica. Curso de Extensão. Departamento de Meteorologia, Centro de Geociências - UFPA, 2004.
SOUZA, Everaldo B. Variabilidade Pluviométrica Intrasazonal sobre a Amazônia Oriental e Nordeste Brasileiro durante o outono austral: Mecanismos Atmosféricos de baixa e alta freqüência. 2003. Tese (Doutorado em Meteorologia) - Universidade de São Paulo, Instituto de Astronomia, Geofísica e Ciências Atmosféricas - Departamento de Ciências Atmosféricas, São Paulo, 2003.

TRENBERTH, K.E. The definition of El Niño. Bulletin of the American Meteorogical Society, v. 78, n. 12, p. 2771-2777, 1997.

UVO, Cíntia Bertacchi. Influence of Sea Surface Temperature on Rainfall and Runnoff in Northeastern South Americ: Analysis and Modeling. 1998. Tese (Doutorado em Meteorologia) - Universidade Lund, Sweden, Departamento de Engenharia de Recursos de Água, 1998.

ZEBIAK, S. E. Air-Sea interaction in the equatorial Atlantic region. J. Climate, v. 6, p. 1567-1586, 1993.

YANAI, M.; ESBENSEN, S.; CHU, J. H. Determination of bulk properties of Tropical cloud clusters from large-scale heat and moisture budgets. Journal of the Atmospheric Sciences, Dept. of Meteorology, University of California, Los Angeles, v. 30, p. 611-627, 1973. 